\title{
Thermal-hydraulic performance of interrupted microchannel heat sinks with different rib geometries in transverse microchambers
}

\author{
Lei Chai ${ }^{\mathrm{a},}$, , Liang Wang ${ }^{\mathrm{b}}$ \\ ${ }^{\text {a }}$ RCUK National Centre for Sustainable Energy Use in Food Chain (CSEF), Brunel University London, Uxbridge, Middlesex UB8 3PH, UK \\ ${ }^{\mathrm{b}}$ Institute of Engineering Thermophysics, Chinese Academy of Sciences, Beijing 100190, China
}

\begin{abstract}
The thermal-hydraulic performance of microchannel heat sinks with ribs in the interrupted transverse microchambers is studied using a three-dimensional conjugated heat transfer model and considering entrance effect, viscous heating and temperature-dependent thermophysical properties. Five different configurations of ribs and four lengths along the flow direction for every rib configuration are selected to analyze the effects of rib geometry on the thermal-hydraulic performance. The five rib configurations are rectangular, backward triangular, diamond, forward triangular and ellipsoidal, and the rib geometry parameters include expansion-constriction profile, ratio and length. The effects of rib geometry on thermal-hydraulic performance are firstly examined by the variations of friction factor and Nusselt number with Reynolds number, and corresponding correlations are proposed. Then, the conductive, convective and fluid capacitive thermal resistances are analyzed to obtain some insight into the basic heat transfer mechanism. Next, the entropy generation rates due to heat transfer and fluid friction are investigated for the analysis of the lost available work and irreversibility in the heat transfer process. Finally, the performance evaluation criteria is calculated to comprehensively assess the performance of such interrupted microchannel heat sinks with different rib geometry. For the studied operation parameters and rib geometries, the interrupted microchannel
\end{abstract}

\footnotetext{
${ }^{*}$ Corresponding author. Tel.: +44 (0)1895 265834.

E-mail address:1.chai@outlook.com (Lei Chai).
} 
heat sinks with ribs in the transverse microchambers show a 4-31\% decrease in the total thermal resistance, a $4-26 \%$ decrease in the total entropy generation rates, the maximum value 1.39 in performance evaluation criteria, compared with the straight microchannel heat sink.

Key words interrupted microchannel; thermal-hydraulic performance; thermal resistance; entropy generation rate; performance evaluation criteria

\section{Introduction}

Since the pioneering work by Tuckerman and Pease [1] in the early 1980s, a great deal of investigations have concentrated on the fluid flow and heat transfer characteristics of microchannel heat sink. Due to its ability to dissipate a large amount of heat from a small area, the microchannel heat sink incorporating single-phase liquid flow has been successfully used in a variety of applications, such as the cooling of electronic devices, automotive heat exchangers, laser process equipment and aerospace technology, etc. However, with the advancements in micro and nano electronics technology, future requirement of heat flux dissipation rate is reaching $1 \mathrm{~kW} / \mathrm{cm}^{2}$ [2]. The traditional straight microchannel heat sink cooling system has become grossly inadequate and imposes limits on product design if no action is taken to develop more effective and innovative cooling methods. To meet such high heat flux removal rate using single-phase liquid, a significant amount of works have been conducted for innovative cooling techniques with the potential to deliver high-heat flux rates for microelectronic applications [3].

$\mathrm{Xu}$ et al. $[4,5]$ used the thermal boundary layer redeveloping concept to demonstrate the interrupted microchannel heat sink which consisted of a set of separated zones adjoining shortened parallel microchannels and transverse microchambers. Chai et al. [3, 6-9] took advantage of the interruption of boundary layer 
formation and establishment of secondary flow to develop the microchannel heat sinks with periodic expansion-constriction cross-sections. Cheng [10], Hong and Cheng [11] and Foong et al [12] based on the enhanced mixing mechanism of cold and hot fluid to introduce the passive microstructures into the microchannels. Combining the advantages of interrupted microchannel and passive microstructures, Chai et al. $[13,14]$ and Wong and Lee [15] introduced the staggered ribs into the transverse microchambers to improve the redeveloping thermal boundary layer. Combining the advantages of streamwise-periodic variations of cross-sectional area and passive microstructures, Xia et al. $[16,17,18]$ and Ghani et al. $[19,20]$ mounted the rectangular ribs into the microchannels with streamwise-periodically changed cross-sections for further heat transfer augmentation. Furthermore, Sidik et al. [21] reviewed the passive techniques for heat transfer augmentation in microchannel heat sink, Ghani et al. [22] comprehensively discussed the effect of channel design on the hydrothermal performance of microchannel heat sink, Dewan and Srivastava [23] reviewed the heat transfer enhancement through flow disruption in a microchannel, and Ghani et al. [24] comprehensively analyzed the effect of manifold zone parameters on hydrothermal performance of microchannel heat sink.

The combined heat transfer enhancement methods generally lead to a much better heat transfer performance, but the application of microchannel heat sink to electronics cooling imposes severe constraints on the system design. For a given heat dissipation rate, the flow rate, pressure drop, fluid temperature rise, and fluid inlet to surface temperature difference requirements necessitate optimization of the heat sink geometry [25]. For the optimal design of microchannel heat sink, several experimental, numerical and theoretical studies have been carried out. Tsai and Reiyu [26] and Liu and Garimella [27] established theoretical optimization models based on thermal resistance minimization for a given pumping power to predict microchannel heat sink performance. Singhal and Garimella [28, 29], Gosselin and Bejan [30], and Canhoto and Reis [31] carried out optimization methods based on the minimization of pumping power requirement for a given thermal resistance to evaluate 
the heat transfer performance. Xie et al. [32] used the relationship between the thermal resistance and the pumping power to evaluate the heat transfer enhancement of the microchannel heat sinks with internal vertical Y-shaped bifurcations. Khan et al. [33], Famouri et al. [34], Shi and Dong [35], Zhai et al. [36], and Chai et al. [37] developed optimization methods based on entropy generation minimization, which was proposed by Bejan [38] for the first time, to study the optimization of thermal and hydraulic resistances simultaneously with all relevant design parameters for microchannel heat sinks including geometric parameters, material properties and flow conditions. Promvonge et al. [39], Xia et al. [40, 41], Chai et al. [13,37], and Zhang et al. [42] used the performance evaluation criteria $(P E C)$ to comprehensively access the heat transfer performance of their proposed microchannel heat sinks.

For the interrupted microchannel heat sink with staggered ribs in the transverse microchambers, Chai et al. [14] has conducted three-dimensional numerical models to examine the local and average friction factor and Nusselt number of single-phase liquid, but they did not investigate the influence of rib geometry parameters and develop the pressure drop and heat transfer correlations, not carefully analyze the heat transfer process and discuss the entropy generation due to heat transfer and fluid friction. Further, as the study for optimal design of the rectangular ribs [13], the rib geometry parameters shows a significant influence on the thermal-hydraulic performance and thus the optimization design of heat sink. Therefore, in this paper, five different shape configurations of ribs are presented and four lengths along the flow direction for each rib configuration are designed to analyze the effect of rib geometry parameters, including expansion-constriction profile, ratio and length, on the thermal-hydraulic performance. The main work of this study is to carefully develop the correlations of pressure drop and heat transfer for such microchannel heat sink, elaborately demonstrate the thermal resistances of heat transfer process for deeper investigation, comprehensively discuss the entropy generation rate due to heat transfer and fluid friction and further the performance evaluation 
criteria for comprehensive evaluations with different operation conditions and rib geometries, with the primary objective to supply accurate data and useful information for the optimal geometry design of such heat sinks.

\section{Model formulation and solution methodology}

\subsection{Geometry structure of microchannel}

The interrupted microchannel heat sink with staggered rectangular ribs in the transverse microchambers studied by Chai et al. [13] is shown in Fig. 1a, which consists of 10 longitudinal microchannels with overall dimensions of $10 \mathrm{~mm}$ in length, $0.35 \mathrm{~mm}$ in height and $2.35 \mathrm{~mm}$ in width. To save the computation time and take advantage of symmetry, a control volume containing a single microchannel and surrounding solid along with the base is selected for developing the fluid flow and heat transfer model as shown in Fig. 1b. The length, width and height of the computational domain are $10 \mathrm{~mm}, 0.25 \mathrm{~mm}$ and $0.35 \mathrm{~mm}$, respectively. The length, width and height for each microchannel region are $2.6 \mathrm{~mm}, 0.1 \mathrm{~mm}$ and $0.2 \mathrm{~mm}$ respectively. The length of the transverse microchamber is $1.1 \mathrm{~mm}$ and the staggered rib is located in its center. In order to study the effects of rib geometry on the thermal-hydraulic performance, five different rib configurations are considered, including rectangular, backward triangular, diamond, forward triangular and ellipsoidal, and four lengths along the flow direction are selected for every rib configuration as shown in Fig. 1c. The five interrupted microchannel heat sinks are respectively named for short as IMCHS-R, IMCHS-BT, IMCHS-D, IMCHS-FT and IMCHS-E. All the staggered ribs are $0.1 \mathrm{~mm}$ in $y$-direction, $0.2 \mathrm{~mm}$ in $z$-direction. The studied four rib lengths along the $x$-direction are $0.2,0.3,0.4$ and $0.5 \mathrm{~mm}$. To study the effects of expansion-constriction profile and ratio of rib geometry, the interrupted microchannel heat sinks are divided into two groups as shown in Fig. 2, one with different profiles (horizontal line, inclined line and ellipsoidal curve) but same 
expansion-constriction ratio (1), including IMCHS-R, IMCHS-D and IMCHS-E, and the other with different expansion-constriction ratios $(0,1$ and $\infty)$ but the same profile (inclined line), including IMCHS-BT, IMCHS-D and IMCHS-FT. Meanwhile, a straight microchannel heat sink without transverse microchamber (MCHS for short) and an interrupted microchannel without ribs (IMCHS for short) are selected for comparison.

\subsection{Numerical model}

A three-dimensional solid-fluid conjugate model has been conducted by Chai et al. $[13,14]$ with the assumptions of steady, developing laminar flow and considerations of temperature-dependent fluid thermal-physical properties and viscous dissipation. The working fluid is water and the heat sink material is silicon. The continuity, momentum and energy equations for the problem can be written as

$$
\begin{aligned}
& \nabla \cdot\left(\rho_{\mathrm{f}} \vec{u}\right)=0 \\
& \nabla \cdot\left(\rho_{\mathrm{f}} \vec{u} \vec{u}\right)=-\nabla p+\nabla \cdot\left[\mu_{\mathrm{f}}\left(\nabla \vec{u}+\nabla \vec{u}^{\mathrm{T}}\right)\right] \\
& \nabla \cdot\left(\rho_{\mathrm{f}} c_{\mathrm{pf}} \vec{u} T\right)=\nabla \cdot\left(k_{\mathrm{f}} \nabla T\right)+\mu_{\mathrm{f}}\left(\nabla \vec{u}+\nabla \vec{u}^{\mathrm{T}}\right) \cdot \nabla \vec{u}
\end{aligned}
$$

where $\vec{u}$ is the fluid velocity vector, $p$ is the hydrodynamic pressure, $\rho_{\mathrm{f}}, \mu_{\mathrm{f}}, c_{\mathrm{pf}}$ and $k_{\mathrm{f}}$ are the water density, dynamic viscosity, specific heat capacity and thermal conductivity, respectively, and calculated from the temperature-dependent property equations of Incropera [43]. The heat conduction equation in the heat sink base is expressed as

$$
\nabla \cdot\left(k_{\mathrm{s}} \nabla T\right)=0
$$

where $k_{\mathrm{s}}$ is the thermal conductivity of silicon and is set as a constant of $148 \mathrm{~W} \cdot \mathrm{m}^{-1} \mathrm{~K}^{-1}$ for the computation.

At the microchannel inlet $(x=0)$, the water velocity $\left(u_{\text {in }}\right)$ and the water temperature $\left(T_{\text {in }}=293 \mathrm{~K}\right)$ are specified. The $u_{\text {in }}$ is assumed uniform in $x$ direction and to be zero in $y$ and $z$ direction and the valves $1,2,3,4$ 
and $5 \mathrm{~m} \cdot \mathrm{s}^{-1}$ are chosen for calculation. The remainder of the computational domain entrance is occupied by the silicon, where the velocities are zero and the surface is adiabatic. At the exit of the computational domain $(x=$ $10 \mathrm{~mm}$ ), a pressure-outlet boundary condition ( $p_{\text {out }}=0$ for gauge pressure) is applied for the microchannel outlet, and zero velocities and adiabatic surface for the silicon. Symmetry is imposed on the left $(y=0.25 \mathrm{~mm})$ and right $(y=0)$ boundaries. At the bottom boundary $(z=0)$, the velocities are zero and a constant heat flux $(q$ $\left.=10^{6} \mathrm{~W} \cdot \mathrm{m}^{-2}\right)$ is imposed at the bottom wall. The top wall $(z=0.35 \mathrm{~mm})$ is assumed to be adiabatic and has zero velocities.

The governing equations were solved using finite-volume-based commercial code, ANSYS FLUENT 12.0. The SIMPLEC algorithm is applied to solve the governing differential equations for the velocity, pressure and temperature fields in the control volume. The convergence criteria is that when the normalized residuals of continuity and momentum and energy equations are less than $10^{-6}$ for all variables. The numerical code is verified in a number of ways to ensure the validity. For every microchannel, a grid independence test is checked using several different mesh sizes. For example, for the IMCHS-R $(l=0.4 \mathrm{~mm})$, various meshes with number of cells ranging from 0.267 to 1.019 million are selected. For the inlet velocity of $4 \mathrm{~m} / \mathrm{s}$, the tested parameters of thermal-hydraulic performance are insensitive to grid refinement (with maximum deviations of $0.43 \%$ for friction factor, $0.76 \%$ for Nusselt number, $0.58 \%$ for total thermal resistance, $0.54 \%$ for total entropy generation rate and $0.91 \%$ for performance evaluation criteria) beyond a mesh of about 0.652 millions. Hence, the 0.652 million grids is used for this mentioned interrupted microchannel. Comparison of numerical results with the corresponding experimental results for the IMCHS-R $(l=0.4 \mathrm{~mm})$ and the MCHS conducted by Chai et al. [14] further ensures the accuracy and reliability of numerical code used in this study.

\section{Data acquisition}


The local Fanning friction factor is defined as

$f_{\mathrm{x}}=\frac{\left(p_{\mathrm{in}}-p_{\mathrm{x}}\right) D_{\mathrm{h}}}{2 \rho_{\mathrm{f}} x u_{\mathrm{m}}^{2}}$

where $p_{\text {in }}$ is the mass-weighted average pressure in the microchannel inlet and $p_{\mathrm{x}}$ is the pressure in the $x$ location. The average Fanning friction factor is given by

$f_{\text {ave }}=\frac{\left(p_{\text {in }}-p_{\text {out }}\right) D_{\mathrm{h}}}{2 \rho_{\mathrm{f}} L u_{\mathrm{m}}^{2}}$

where $L$ is the length of the interrupted microchannel heat sink, $p_{\text {out }}$ is the pressure in the microchannel outlet and assumed to be 0 . The local convective heat transfer coefficient and the local Nusselt number are defined as

$$
\begin{aligned}
& h_{\mathrm{x}}=\frac{q L W}{A\left(T_{\mathrm{w}, \mathrm{x}}-T_{\mathrm{f}, \mathrm{x}}\right)} \\
& N u_{\mathrm{x}}=\frac{h_{\mathrm{x}} D_{\mathrm{h}}}{k_{\mathrm{f}}}
\end{aligned}
$$

where $q$ represents heat flux at the heat sink base, $A$ is the contact surface area of water and silicon for a single microchannel, $W$ is the width of computational domain, $k_{\mathrm{f}}$ is the mass average fluid thermal conductivity, $T_{\mathrm{w}, \mathrm{x}}$ and $T_{\mathrm{f}, \mathrm{x}}$ are the local heat sink base temperature and the local bulk fluid temperature. The average heat transfer coefficient and Nusselt number can be obtained by

$$
\begin{aligned}
& h_{\text {ave }}=\frac{1}{L} \int h_{\mathrm{x}} d x \\
& N u_{\text {ave }}=\frac{1}{L} \int N u_{\mathrm{x}} d x
\end{aligned}
$$

The Reynolds number and pumping power are defined as

$$
\begin{aligned}
& R e=\frac{\rho_{\mathrm{f}} u_{\mathrm{m}} D_{\mathrm{h}}}{\mu_{\mathrm{f}}} \\
& P_{\mathrm{p}}=\Delta p_{\text {mic }} \stackrel{\stackrel{\mathrm{g}}{V}}{=} \frac{\Delta p_{\text {mic }} \stackrel{\mathrm{g}}{m}}{\rho_{\mathrm{f}}}
\end{aligned}
$$

where $\mu_{\mathrm{f}}$ is the mass average fluid dynamic viscosity, $\stackrel{g}{V}$ is the fluid volume flow rate, $\Delta p_{\text {mic }}$ is the pressure drop in the microchannel heat sink $\Delta p_{\text {mic }}=p_{\text {in }}-p_{\text {out. }}$

In order to obtain some insight into the basic mechanisms and properties of microchannel heat sinks, 
Loosen [44] proposed a simplified one-dimensional analytical model to study the thermal resistance. The total thermal resistance has been described as the sum of three series resistances, including the conductive term, the convective term and the capacitive term. The conductive term describes the conduction of the heat through the base of heat sink to the cooling fins, the convective term describes the heat transition from the solid material of the fins to the liquid coolant, and the capacitive term describes the temperature increase of the coolant while through the heat sink.

$R_{\mathrm{th}}=\frac{T_{\mathrm{w}}-T_{\text {in }}}{Q}=\frac{T_{\mathrm{w}}-T_{\text {cont }}}{Q}+\frac{T_{\text {cont }}-T_{\mathrm{f}}}{Q}+\frac{T_{\mathrm{f}}-T_{\text {in }}}{Q}=R_{\text {cond }}+R_{\text {conv }}+R_{\text {cap }}$

where $R_{\text {cond }}, R_{\text {conv }}$ and $R_{\text {cap }}$ are respectively the conductive part, convective part and the capacitive part thermal resistance, $R_{\mathrm{th}}$ is the total thermal resistance, $Q$ is the heat transfer rate, $T_{\mathrm{w}}$ is the area-weighted temperature of the silicon base, $T_{\text {cont }}$ is the area-weighted temperature of the interior walls of the channel, $T_{\mathrm{f}}$ is the mass-average bulk fluid temperature and $T_{\text {in }}$ is the set fluid temperature in the microchannel inlet.

Entropy generation rate can be used to evaluate the irreversibility of flow and heat transfer process. Khan et al. [33] proposed an entropy generation minimization procedure to optimize the overall performance of microchannel heat sinks. This procedure allowed the combined effect of thermal resistance and pressure drop to be assessed simultaneously as the heat sink interacts with the surrounding flow field. General expressions for the entropy generation rate were developed by considering an appropriate control volume and applying mass, energy, and entropy balance.

$S_{\text {gen }}=\frac{Q\left(T_{\mathrm{w}}-T_{\mathrm{a}}\right)}{T_{\mathrm{w}} T_{\mathrm{a}}}+\frac{\stackrel{\mathrm{g}}{m}\left(p_{\text {in }}-p_{\text {out }}\right)}{\rho_{\mathrm{f}} T_{\mathrm{a}}}=S_{\mathrm{gen, \textrm {h }}}+S_{\mathrm{gen}, \mathrm{f}}$

where $T_{\mathrm{a}}$ is the ambient temperature and assumed to $T_{\mathrm{a}}=T_{\mathrm{in}}, p_{\text {in }}$ and $p_{\text {out }}$ are the pressures in the microchannel inlet and outlet, $\stackrel{\mathrm{g}}{m}$ is the fluid mass flow rate, $S_{\mathrm{gen}}$ is the total entropy generation rate, and $S_{\mathrm{gen}, \mathrm{h}}$ and $S_{\mathrm{gen}, \mathrm{f}}$ are the entropy generation rates due to heat transfer and fluid friction, respectively.

In order to access the enhanced heat transfer surfaces in heat exchanger design, Webb [45] outlined detailed 
procedures to calculate the performance improvement and to select the optimum surface geometry. For the interrupted microchannel heat sink, the performance evaluation criteria is defined as the ratio of their heat transfer coefficients $\left(h_{\mathrm{ave}}\right)$ to that of the conventional MCHS $\left(h_{\mathrm{ave}, 0}\right)$ at an equal pumping power.

$P E C=\left.\frac{h_{\text {ave }}}{h_{\text {ave, } 0}}\right|_{\mathrm{pp}}=\left.\frac{N u_{\text {ave }}}{N u_{\text {ave }, 0}}\right|_{\mathrm{pp}}=\frac{N u_{\text {ave }} / N u_{\text {ave }, 0}}{\left(f_{\text {ave }} / f_{\text {ave }, 0}\right)^{1 / 3}}$

where $N u_{\text {ave }, 0}$ and $f_{\text {ave }, 0}$ respectively stand for Nusselt number and friction factor of the MCHS.

To further clearly show the effect of ribs on fluid flow and heat transfer performance, the performance of IMCHS are used as reference base to calculate the $P E C$ and given by

$P E C_{\mathrm{IM}}=\left.\frac{h_{\text {ave }}}{h_{\text {ave, }, \mathrm{M}}}\right|_{\mathrm{pp}}=\left.\frac{N u_{\mathrm{ave}}}{N u_{\mathrm{ave}, \mathrm{IM}}}\right|_{\mathrm{pp}}=\frac{N u_{\text {ave }} / N u_{\text {ave,IM }}}{\left(f_{\text {ave }} / f_{\text {ave, IM }}\right)^{1 / 3}}$

where $N u_{\text {ave,IM }}$ and $f_{\text {ave,IM }}$ respectively stand for Nusselt number and friction factor of the IMCHS.

\section{Results and discussion}

\subsection{Friction factor and Nusselt number}

Figures 3 and 4 respectively show the friction factor ratio $\left(\eta_{\mathrm{f}}=f_{\text {ave }} / f_{\text {ave }, 0}\right)$ and Nusselt number ratio $\left(\eta_{\mathrm{h}}=\right.$ $\left.N u_{\text {ave }} / N u_{\text {ave, }, 0}\right)$ of the interrupted microchannel heat sinks to the MCHS as Re ranging from 187 to 715 . It can be observed that $\eta_{\mathrm{f}}$ increase quickly with increase of $R e$, especially for IMCHS-R and IMCHS-BT which show obviously higher increase velocity than the others, and the IMCHS-D with $l=0.3 \mathrm{~mm}$ shows the lowest $\eta_{\mathrm{f}}$ indicating the smallest pressure drop. The $\eta_{\mathrm{h}}$ also increase with increase of $R e$, but the increase velocity becomes smaller and is lower than $\eta_{\mathrm{f}}$ with $R e$, indicating that the ribs gradually lost its advantage as an effective heat transfer enhancement method due to the larger pressure drop penalty. As shown in Fig. 5 and mentioned by Chai et al. [14], three effects influence pressure drops across the interrupted microchannels with ribs: the pressure recovery effect in the microchamber leads to decrease of $f_{\mathrm{x}}$, the head loss when liquid leaves 
the microchamber and enters the next zone results in higher $f_{\mathrm{x}}$ in the next microchannel region, and under the influence of staggered ribs, the $f_{\mathrm{x}}$ can reach a much higher value in the next microchannel region. With the increase of $R e$, the last two effects significantly enhance, resulting in the much larger $\eta_{\mathrm{f}}$. There are two main effects on heat transfer enhancement of such interrupted microchannels: the mixing of cold and hot water in microchamber and the redeveloping of thermal boundary layer in the microchannel region. The transverse microchambers interrupt the thermal boundary layer, the staggered ribs promote the local heat transfer in the microchannel regions to a much higher redeveloping level, and the different rib geometry parameters lead to different redeveloping levels. Results also indicate that the expansion-constriction profile and ratio have much influence on $\eta_{\mathrm{f}}$, while rib length shows less; and the expansion-constriction profile and ratio have less influence on $\eta_{\mathrm{h}}$ than $\eta_{\mathrm{f}}$, while rib length shows more. For $R e$ in the range of 187 to 715 , with increase of rib length from $0.2 \mathrm{~mm}$ to $0.5 \mathrm{~mm}$ for each interrupted microchannel heat sinks, the difference of $\eta_{\mathrm{f}}$ is less than $7 \%$, while the maximum increases of $\eta_{\mathrm{h}}$ are $9 \%, 7 \%, 10 \%, 7 \%$ and $12 \%$ respectively for IMCHS-R, IMCHS-BT, IMCHS-D, IMCHS-FT and IMCHS-E.

To predict the friction factor and Nusselt number in the proposed interrupted microchannel heat sink, the correlations of $\eta_{\mathrm{f}}$ and $\eta_{\mathrm{h}}$ are deduced by least squares method based on 180 pressure drop data and 180 heat transfer data points, respectively, as follows:

$$
\begin{aligned}
& \eta_{\mathrm{f}}=\operatorname{aRe}^{b}\left(\frac{l}{w}\right)^{c} \\
& \eta_{\mathrm{h}}=d \operatorname{Re}^{e}\left(\frac{l}{w}\right)^{f}
\end{aligned}
$$

where $l$ and $w$ are respectively the rib length and width. The constants $a, b, c, d, e$, and $f$ are investigated according to the rib geometries and shown in Table 1. Fig. 6 shows a comparison of the values of the numerical simulation and predicted by the above correlations for the studied Re range. It can be found excellent agreement between simulation and prediction with deviation less than $5 \%$. 


\subsection{Thermal resistance and pumping power}

Figure 7 shows the variation of $R_{\text {th }}$ with $R e$ in the range of 187 to 715 for the interrupted microchannel heat sinks. It can be seen that with increase of $R e$, the $R_{\text {th }}$ drops quickly for all the microchannel heat sinks. This is caused by the decrease of $R_{\text {conv }}$ and $R_{\text {cap }}$ with increase of $R e$ as shown in Fig. 8 . The increase of heat transfer coefficient with $R e$ leads to the decrease of $R_{\text {conv }}$, and the increase of $R e$ means the increased mass flow rate, which leads to the lower temperature at the microchannel outlet and thus the decrease of $R_{\text {cap. }}$ It is noticed that for a given $R e, R_{\mathrm{th}}$ of IMCHS is much lower than that of the MCHS, and $R_{\mathrm{th}}$ for the interrupted microchannel heat sinks with $l=0.5 \mathrm{~mm}$ is lower again than that for the IMCHS, indicating better heat transfer performance caused by the transverse microchamber and the staggered ribs. And with increase of $R e$, the difference of $R_{\mathrm{th}}$ between IMCHS and MCHS rises, while the difference between the interrupted microchannel heat sinks with ribs and IMCHS drops. For example, the difference of $R_{\text {th }} 0.2 \mathrm{KW}^{-1}$ between IMCHS and MCHS at $R e=187$ becomes $1.6 \mathrm{KW}^{-1}$ at $R e=715$, while the difference about $1.7 \mathrm{KW}^{-1}$ between the interrupted microchannel heat sinks with ribs and IMCHS at $R e=187$ becomes $0.7 \mathrm{KW}^{-1}$ at $R e=715$, which indicates that the heat transfer enhancement caused by the staggered ribs is more obvious at lower $R e$, while that caused by the transverse microchamber is more notable at higher $R e$. For $R e$ ranging from 187 to 715 , there is a $1-21 \%$ decrease of $R_{\mathrm{th}}$ for IMCHS, there are $14-31 \%, 12-30 \%, 11-30 \%, 12-29 \%$, and $13-31 \%$ decrease of $R_{\mathrm{th}}$ for IMCHS-R $(l=0.5 \mathrm{~mm})$, IMCHS-BT $(l=0.5 \mathrm{~mm}), \operatorname{IMCHS}-\mathrm{D}(l=0.5 \mathrm{~mm}), \operatorname{IMCHS}-\mathrm{FT}(l=0.5 \mathrm{~mm})$ and IMCHS-E $(l=0.5 \mathrm{~mm})$, respectively, in contrast with MCHS. From Fig. 8 , it can be also found that with increase of $R e$, the conductive thermal resistance ratio $\left(R_{\text {cond }} / R_{\text {th }}\right)$ shows a slight increase due to the decrease of $R_{\mathrm{th}}$, the convective thermal resistance ratio $\left(R_{\mathrm{conv}} / R_{\mathrm{th}}\right)$ first increases and then flattens, and the capacitive thermal resistance ratio $\left(R_{\text {cap }} / R_{\mathrm{th}}\right)$ decreases rapidly at first and then slowly. For $R e$ ranging from 187 to 715 , 
the $R_{\text {cond }} / R_{\text {th }}$ is no more than $8 \%$ for all the microchannels, the $R_{\text {conv }} / R_{\text {th }}$ are respectively $57-78 \%, 56-72 \%$ and $51-70 \%$ for MCHS, IMCHS and IMCHS-E $(l=0.5 \mathrm{~mm})$, while the $R_{\text {cap }} / R_{\text {th }}$ are respectively $40-16 \%, 40-20 \%$ and $46-23 \%$ for MCHS, IMCHS and IMCHS-E $(l=0.5 \mathrm{~mm})$.

Besides evaluating the heat transfer performance to $R e$, the $R_{\text {th }}$ is always compared between each other under the constant pumping power constraint. Fig. 9a shows the relationship between $R_{\mathrm{th}}$ and $P_{\mathrm{p}}$. For a given $P_{\mathrm{p}}$, a lower $R_{\mathrm{th}}$ suggests a better heat transfer performance. Based on this consideration with the same value of pumping power, the $R_{\mathrm{th}}$ of the interrupted microchannels is obviously lower than MCHS, and those of the interrupted microchannel heat sinks with ribs is lower again than the IMCHS. For instance, at $P_{\mathrm{p}}=8 \times 10^{-3} \mathrm{~W}$, the corresponding $R_{\text {th }}$ is about $17 \%$ lower for IMCHS, and about $28 \%$ lower for the interrupted microchannel heat sinks with ribs, based on the MCHS. It is noted that with increase of $P_{\mathrm{p}}$, the $R_{\mathrm{th}}$ reduces dramatically at low $P_{\mathrm{p}}$ and the drop velocity continues to moderate at high $P_{\mathrm{p}}$, especially for the interrupted microchannel heat sinks with ribs. This tendency is caused by the variation of $R_{\mathrm{th}}$ and $P_{\mathrm{p}}$ with $R e$. The variation of $R_{\mathrm{th}}$ and with $R e$ is shown in Fig. 7, and the relationship of $P_{\mathrm{p}}$ and $R e$ is shown in Fig. $9 \mathrm{~b}$. With increase of $R e$, the $P_{\mathrm{p}}$ for the interrupted microchannel heat sinks increase rapidly and are obviously higher than those of MCHS, partly leading to the rapid drop of $R_{\text {th }}$ with $P_{\mathrm{p}}$.

Figure 10 shows the variation of $R_{\mathrm{th}}$ with $P_{\mathrm{p}}$ for the interrupted microchannels with different rib geometries. It can be seen that there is only a little change of $R_{\text {th }}$ with $P_{\mathrm{p}}$ for different rib geometries, indicating the relationship between $R_{\mathrm{th}}$ and $P_{\mathrm{p}}$ is not very clear to present the comprehensive thermal-hydraulic performance.

\subsection{Entropy generation rate}

Figure 11 shows the variation of $S_{\text {gen }}$ and ratio $\left(\eta_{\mathrm{S}}=S_{\text {gen }} / S_{\text {gen, },}\right)$ to the MCHS with $R e$ from 187 to 715 . It can be clearly seen that with increase of $R e$, the $S_{\text {gen }}$ drops quickly for all the microchannel heat sinks. For a 
given $R e, S_{\text {gen }}$ for IMCHS is much lower than that for the MCHS and $S_{\text {gen }}$ for the interrupted microchannel heat sinks with ribs is lower again than that for the IMCHS. For Re ranging from 187 to 715 , there is a $1-18 \%$ decrease of $S_{\text {gen }}$ for IMCHS, there are $13-24 \%, 11-24 \%, 10-25 \%, 11-24 \%$, and $12-25 \%$ decrease of $S_{\text {gen }}$ for IMCHS-R $(l=0.5 \mathrm{~mm})$, IMCHS-BT $(l=0.5 \mathrm{~mm})$, IMCHS-D $(l=0.5 \mathrm{~mm})$, IMCHS-FT $(l=0.5 \mathrm{~mm})$ and IMCHS-E $(l=0.5 \mathrm{~mm})$, respectively, compared with MCHS. Fig. 12 shows the variation of $S_{\text {gen,h }}$ and $S_{\text {gen,f }}$ with $R e$. It is noted that $S_{\text {gen,h }}$ is much higher than $S_{\text {gen,f }}$ for a given $R e$. For the three micochannel heat sinks,

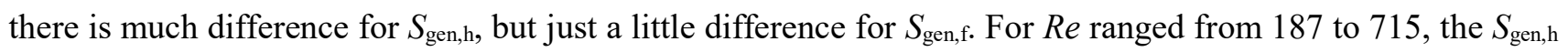
is in the range of $9.66 \times 10^{-4}-5.22 \times 10^{-4}, 9.56 \times 10^{-4}-4.18 \times 10^{-4}$ and $8.53 \times 10^{-4}-3.69 \times 10^{-4}$ for MCHS, IMCHS and IMCHS-E $(l=0.5 \mathrm{~mm})$, respectively; the $S_{\mathrm{gen}, \mathrm{f}}$ is in the range of $7.65 \times 10^{-7}-2.88 \times 10^{-5}, 7.24 \times 10^{-7}-3.53 \times 10^{-5}$ and $8.04 \times 10^{-7}-4.09 \times 10^{-5}$ for MCHS, IMCHS and IMCHS-E $(l=0.5 \mathrm{~mm})$, respectively. Due to the very little

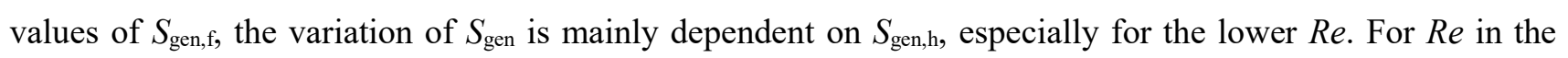
range of 187 to $715, S_{\mathrm{gen}, \mathrm{h}} / S_{\mathrm{gen}}$ is $99.9-94.7 \%, 99.9-92.2 \%$ and $99.9-89.9 \%$ for MCHS, IMCHS and IMCHS-E ( $l=0.5 \mathrm{~mm})$, respectively. The variation of $S_{\mathrm{gen}, \mathrm{h}}$ and $S_{\mathrm{gen}, \mathrm{f}}$ with $R e$ can be explained by the relationships with $N u_{\text {ave }}$ and $R e$ as the following equations. Combining $S_{\text {gen, } \mathrm{h}}=\frac{Q\left(T_{\mathrm{w}}-T_{\mathrm{a}}\right)}{T_{\mathrm{w}} T_{\mathrm{a}}}, \quad Q=h_{\text {ave }} A_{\text {con }}\left(T_{\mathrm{w}}-T_{\mathrm{f}}\right)=\stackrel{\mathrm{g}}{m} c_{\mathrm{p}}\left(T_{\text {out }}-T_{\text {in }}\right)$, $\stackrel{\mathrm{g}}{m}=\frac{\operatorname{Re} \mu \mathrm{f} A_{\text {mic }}}{D_{\mathrm{h}}}, N u_{\text {ave }}=\frac{h_{\text {ave }} D_{\mathrm{h}}}{k_{\mathrm{f}}}$, the $S_{\text {gen,h }}$ can be written as

$S_{\mathrm{gen}, \mathrm{h}}=Q\left(\frac{1}{T_{\mathrm{a}}}-\frac{1}{\left.T_{\mathrm{in}}+\frac{Q D_{\mathrm{h}}}{A_{\mathrm{con}} N u_{\mathrm{ave}} k_{\mathrm{f}}}+\frac{Q D_{\mathrm{h}}}{2 \operatorname{Re} \mu \mathrm{f} A_{\mathrm{mic}} c_{\mathrm{p}}}\right)}\right.$

If it is assumed that $T_{\mathrm{a}}=T_{\mathrm{in}}$, then

$$
\begin{aligned}
& S_{\text {gen, } \mathrm{h}}=Q\left(\frac{1}{T_{\text {in }}}-\frac{1}{T_{\text {in }}+Q D_{\mathrm{h}}\left(C_{1}+C_{2}\right)}\right) \\
& C_{1}=\frac{1}{A_{\text {con }} N u_{\text {ave }} k_{\mathrm{f}}} \\
& C_{2}=\frac{1}{2 \operatorname{Re} \mu A_{\text {mic }} c_{\mathrm{p}}}
\end{aligned}
$$

From Eqs. (19) and (20), it can be noted that the $S_{\text {gen, }}$ depends on $N u_{\text {ave }}$ and $R e$. Increases of $N u_{\text {ave }}$ and $R e$ leads to the decreases of $C_{1}$ and $C_{2}$ and further the decrease $S_{\text {gen,h. }}$. Specially, the increase of $R e$ also leads to 
the increase of $N u_{\text {ave, }}$ which causes the substantial reduction of $S_{\text {gen, }}$ at the combined effects of $N u_{\text {ave }}$ and $R e$. For a given $R e$, the $S_{\text {gen,h }}$ only depends on the $N u_{\text {ave }}$ and with increase of $N u_{\text {ave, }}$, the $S_{\text {gen,h }}$ decrease. For the interrupted microchannel heat sinks with ribs at a given $R e$, the much higher $N u_{\text {ave }}$ leads to the obvious decrease of $S_{\text {gen, } \mathrm{h} \cdot}$ Combining $S_{\text {gen, }}=\frac{\stackrel{g}{m}\left(p_{\text {in }}-p_{\text {out }}\right)}{\rho_{\mathrm{f}} T_{\mathrm{a}}}, \stackrel{\mathrm{g}}{m}=\frac{R e \mu \mathrm{f} A_{\text {mic }}}{D_{\mathrm{h}}}, \quad p_{\text {in }}-p_{\text {out }}=\frac{2 f_{\text {ave }} \rho_{\mathrm{f}} L u_{\mathrm{m}}{ }^{2}}{D_{\mathrm{h}}}, T_{\mathrm{a}}=T_{\text {in }}$, the $S_{\text {gen, } \mathrm{f}}$ can be written as

$S_{\text {gen,f }}=\frac{2 L\left(f_{\text {ave }} R e\right) R e^{2} \mu \mathrm{f}^{3} A_{\text {mic }}}{D_{\mathrm{h}}^{2} \rho_{\mathrm{f}}^{2} T_{\text {in }}}$

From Eq. (21), it can be seen that the $S_{\text {gen,f }}$ depends on $f_{\text {ave }} R e$ and $R e$. As mentioned in Chai et al. [14], the $f_{\text {ave }} R e$ shows an approximately linear increase with increase of $R e$. Therefore, there is almost a linear relationship between $S_{\mathrm{gen,f}}$ and $R e^{3}$, and the increase of $R e$ results in significantly substantial rise of $S_{\mathrm{gen,f} .}$ The variation of $S_{\text {gen, }}$ with $R e$ can be also explained by the relationships with $R_{\mathrm{th}}$.

$$
S_{\mathrm{gen, \textrm {h }}}=Q\left(\frac{1}{T_{\mathrm{a}}}-\frac{1}{T_{\mathrm{w}}}\right)=Q\left(\frac{1}{T_{\mathrm{a}}}-\frac{1}{T_{\mathrm{in}}+Q R_{\mathrm{th}}}\right)=Q\left(\frac{1}{T_{\mathrm{in}}}-\frac{1}{T_{\mathrm{in}}+Q R_{\mathrm{th}}}\right)
$$

From Eq (22) it can be noticed that the $S_{\mathrm{gen}, \mathrm{h}}$ depends on $R_{\mathrm{th}}$, and decrease of $R_{\mathrm{th}}$ leads to the decrease of $S_{\mathrm{gen}, \mathrm{h}}$.

Thus the relationship between $R_{\mathrm{th}}$ and $R e$ as shown in Fig. 7 indicates the variation of $S_{\text {gen,h }}$ with $R e$ as shown in Fig. 12. From Eqs. (20) and (22), the variation of $R_{\text {th }}$ with $N u_{\text {ave }}$ and $R e$ can be obtained as shown in Eq

$$
R_{\mathrm{th}}=D_{\mathrm{h}}\left(\frac{1}{A_{\mathrm{con}} N u_{\mathrm{ave}} k_{\mathrm{f}}}+\frac{1}{2 \operatorname{Re} \mu \mathrm{f} A_{\text {mic }} c_{\mathrm{p}}}\right)=D_{\mathrm{h}}\left(C_{1}+C_{2}\right)
$$

The variation of $S_{\mathrm{gen}, \mathrm{f}}$ with $R e$ can be also explained by the relationships with $P_{\mathrm{p}}$. Combining $S_{\text {gen,f }}=\frac{\stackrel{\mathrm{g}}{m}\left(p_{\text {in }}-p_{\text {out }}\right)}{\rho_{\mathrm{f}} T_{\mathrm{a}}}$ and $P_{\mathrm{p}}=\frac{\left(p_{\text {in }}-p_{\text {out }}\right) \stackrel{\mathrm{g}}{m}}{\rho_{\mathrm{f}}}$, the $S_{\text {gen, } \mathrm{f}}$ can also be written as $S_{\mathrm{gen, \textrm {f }}}=\frac{P_{\mathrm{p}}}{T_{\mathrm{in}}}$

From Eq (24) it can be noticed that the $S_{\text {gen,f }}$ linearly varies with $P_{\mathrm{p}}$, and the slope factor is $1 / T_{\text {in. }}$ Thus the relationship between $P_{\mathrm{p}}$ and $R e$ as shown in Fig. $9 \mathrm{~b}$ clearly indicates the variation of $S_{\text {gen,f }}$ with $R e$ as shown in 
Fig. 12. From Eqs. (21) and (24), the variation of $P_{\mathrm{p}}$ with $R e$ can be obtained as shown in Eq (25).

$$
P_{\mathrm{p}}=\frac{2 L\left(f_{\text {ave }} R e\right) R e^{2} \mu \mathrm{f}^{3} A_{\text {mic }}}{D_{\mathrm{h}}{ }^{2} \rho_{\mathrm{f}}{ }^{2}}
$$

Figure 13 shows the variation of $\eta_{\mathrm{s}}$ with $R e$ for the interrupted microchannel heat sinks with different rib geometries. Generally, the variation of $\eta_{\mathrm{s}}$ with $R e$ can clearly evaluate the comprehensive thermal-hydraulic performance of heat sinks for a given $R e$. The IMCHS-R and IMCHS-FT with $l=0.5 \mathrm{~mm}$ shows the best performance and IMCHS-D with $l=0.4 \mathrm{~mm}$ presents the worst, because of $S_{\text {gen }}$ mainly depends on $S_{\text {gen,h. }}$.

\subsection{Performance evaluation criteria}

Fig. 14 shows the variation of $P E C$ with $R e$ for the interrupted microchannels with different rib geometries. It can be found that the variation of $P E C$ with $R e$ can obviously present the comprehensive thermal-hydraulic performance of heat sinks for a given $P_{\mathrm{p}}$, which clearly demonstrate the effect of rib geometry, that the IMCHS-E $(l=0.5 \mathrm{~mm})$ shows the best heat transfer performance, while IMCHS-BT $(l=$ $0.2 \mathrm{~mm}$ ) shows the worst. This behavior can be explained by the effects of rib geometry parameters on fluid flow and heat transfer as shown in Figs. 3 and 4 that IMCHS-E $(l=0.5 \mathrm{~mm})$ performs a higher $\eta_{\mathrm{h}}$ and a moderate $\eta_{\mathrm{f}}$ while IMCHS-BT $(l=0.2 \mathrm{~mm})$ shows the largest $\eta_{\mathrm{f}}$ but a lower $\eta_{\mathrm{h}}$. With an increase of $R e, P E C$ for IMCHS always increases, but PEC for the interrupted microchannel heat sinks with ribs shows different tendencies. For IMCHS-R, $P E C$ firstly increases and then reduces after about $R e=450$. For the other interrupted microchannels with ribs, $P E C$ always increases with increase of $R e$, but the increase velocity of $P E C$ with $R e$ becomes slower. The IMCHS-D $(l=0.5 \mathrm{~mm})$ shows the fastest increase velocity for $P E C$ with $R e$ and IMCHS-BT $(l=0.2 \mathrm{~mm})$ shows the slowest. It also can be seen that there is an obvious increase of $P E C$ with increase of rib length. For example, with increase of rib length from $0.2 \mathrm{~mm}$ to $0.5 \mathrm{~mm}, P E C$ is from $1.24,1.24,1.28,1.29$ and 1.30 to $1.31,1.30,1.38,1.36$ and 1.39 respectively for IMCHS-R, IMCHS-BT, 
IMCHS-D, IMCHS-FT and IMCHS-E, at $R e=715$.

Figure 15 show the variation of $P E C_{\mathrm{IM}}$ with $R e$ for the interrupted microchannels with different rib geometries. It can be seen that the $P E C_{\mathrm{IM}}$ shows an obvious decrease with $R e$, clearly indicating that the staggered ribs in the transverse microchambers gradually lost its advantage used as an effective heat transfer enhancement method with increase of $R e$. For example, with increase of Re from 187 to 715 and decrease of rib length from $0.5 \mathrm{~mm}$ to $0.2 \mathrm{~mm}, P E C_{\mathrm{IM}}$ decrease from $1.21,1.17,1.18,1.18$ and 1.21 to $1.01,1.00,1.03$, 1.05 and 1.05 respectively for IMCHS-R, IMCHS-BT, IMCHS-D, IMCHS-FT and IMCHS-E.

\section{Conclusions}

The thermal-hydraulic performance of the proposed interrupted microchannel heat sinks have been studied with the variations of friction factor and Nusselt number, the conductive, convective and fluid capacitive thermal resistances in the heat transfer process, the entropy generation rate due to heat transfer and fluid friction and performance evaluation criteria based on both MCHS and IMCHS. The effect of rib geometry parameters on the thermal-hydraulic performance has been investigated that the expansion-constriction profile and ratio of rib geometry have obvious influence on friction factor, while rib length shows more effect on Nusselt number. Based on the numerical simulation data, the empirical correlations for $\eta_{\mathrm{f}}$ and $\eta_{\mathrm{h}}$ are proposed for the five rib configurations, respectively, rectangular, backward triangular, diamond, forward triangular and ellipsoidal. For the thermal resistances and pumping power, an increase of $R e$ leads to the decreases of $R_{\text {conv }}$, $R_{\text {cap }}$ and thus $R_{\mathrm{th}}$, but also results in the rapid increase of $P_{\mathrm{p}}$. The variation of $R_{\mathrm{th}}$ with $P_{\mathrm{p}}$ for the interrupted microchannels with different rib geometries change very little, making it not to be a good criteria for the comprehensive thermal-hydraulic performance evaluation. For the entropy generation rate, $S_{\text {gen, }}$ is much higher than $S_{\mathrm{gen}, \mathrm{f}}$ for a given $R e$, making the variation of $S_{\mathrm{gen}}$ with $R e$ mainly depends on $S_{\mathrm{gen}, \mathrm{h}}$ with $R e$. The 
formulas of $S_{\text {gen,h }}$ with $N u_{\text {ave }}$ and $R e, S_{\text {gen,f }}$ with $R e, S_{\text {gen,h }}$ with $R_{\text {th }}, R_{\text {th }}$ with $N u_{\text {ave }}$ and $R e, S_{\text {gen,f }}$ with $P_{\mathrm{p}}, P_{\mathrm{p}}$ with $R e$ are obtained and analyzed. Generally, the variations of $S_{\mathrm{gen}}$ or $\eta_{\mathrm{s}}$ with $R e$ can clearly evaluate the comprehensive thermal-hydraulic performance of heat sinks for a given $R e$ or mass flow rate or mass flux, where the IMCHS-R and IMCHS-FT with $l=0.5 \mathrm{~mm}$ shows the best performance. For the performance evaluation criteria, the variation with $R e$ clearly demonstrates the effect of rib geometry, which can obviously present the comprehensive thermal-hydraulic performance of heat sinks for a given $P_{\mathrm{p}}$ where the IMCHS-E with $l=0.5 \mathrm{~mm}$ performs the best, and the further study indicates that the staggered ribs in the transverse microchambers can obviously enhance the thermal-hydraulic performance of such heat sinks, but gradually lost its advantage used as an effective method with increase of $R e$. 


\section{Acknowledgements}

The work was supported by the Engineering and Physical Sciences Research Council (EPSRC) of the UK through research grant (RRR1025R33470) and the Youth Innovation Promotion Association of CAS (2016131). 


\section{References}

[1] D.B. Tuckerman, R.F.W. Pease, High-performance heat sinking for VLSI, IEEE Electron Device Letters 2 (1981) 126-129.

[2] S.G. Kandlikar, S. Colin, Y. Peles, S. Garimella, R.F. Pease, J.J. Brandner, D.B. Tuckerman, Heat transfer in microchannels-2012 status and research needs, Journal of Heat Transfer 135 (2013) 091001.

[3] L. Chai, G.D. Xia, L. Wang, Heat transfer enhancement in microchannel heat sinks with periodic expansion-constriction cross-sections, International Journal of Heat and Mass Transfer 62 (2013) $741-751$.

[4] J.L. Xu, Y.H. Gan, D.C. Zhang, Microscale heat transfer enhancement using thermal boundary layer redeveloping concept, International Journal of Heat and Mass Transfer 48 (2005) 1662-1674.

[5] J.L Xu, Y.X Song, W. Zhang, Numerical simulations of interrupted and conventional microchannel heat sinks, International Journal of Heat and Mass Transfer 51 (2008) 5906-5917.

[6] L. Chai, G.D. Xia, M.Z. Zhou, Numerical simulation of fluid flow and heat transfer in a microchannel heat sink with offset fan-shaped reentrant cavities in sidewall, International Communications in Heat and Mass Transfer 38 (2011) 577-584.

[7] L. Chai, G.D. Xia, H.S. Wang, Numerical study of laminar flow and heat transfer in microchannel heat sink with offset ribs on sidewalls, Applied Thermal Engineering 92 (2016) 32-41

[8] L. Chai, G.D. Xia, H.S. Wang, Parametric study on thermal and hydraulic characteristics of laminar flow in microchannel heat sink with fan-shaped ribs on sidewalls-Part 1: Heat transfer, International Journal of Heat and Mass Transfer 97 (2016) 1069-1080.

[9] L. Chai, G.D. Xia, H.S. Wang, Parametric study on thermal and hydraulic characteristics of laminar 
flow in microchannel heat sink with fan-shaped ribs on sidewalls-Part 2: Pressure drop, International Journal of Heat and Mass Transfer 97 (2016) 1081-1090.

[10] Y.J. Cheng, Numerical simulation of stacked microchannel heat sink with mixing-enhanced passive structure, International Communications in Heat and Mass Transfer 34 (2007) 295-303.

[11] F. Hong P. Cheng, Three dimensional numerical analyses and optimization of offset strip-fin microchannel heat sinks, International Communications in Heat and Mass Transfer 36 (2009) 651-656.

[12] A.J. Foong, N. Ramesh, Laminar convective heat transfer in a microchannel with internal longitudinal fins, International Journal of Thermal Sciences 48 (2009) 1908-1913.

[13] L. Chai, G.D. Xia, M. Zhou, J. Li, J. Qi, Optimum thermal design of interrupted microchannel heat sink with rectangular ribs in the transverse microchambers, Applied Thermal Engineering 51 (2013) $880-889$.

[14] L. Chai, G.D. Xia, H.S. Wang, Laminar flow and heat transfer characteristics of interrupted microchannel heat sink with ribs in the transverse microchambers, International Journal of Thermal Sciences $110(2016) 1-11$.

[15] K.C. Wong, J.H. Lee, Investigation of thermal performance of microchannel heat sink with triangular ribs in the transverse microchambers, International Communications in Heat and Mass Transfer 65 (2015) $103-110$.

[16] G.D. Xia, Y.L. Zhai, Z.Z. Cui, Numerical investigation of thermal enhancement in a micro heat sink with fan-shaped reentrant cavities and internal ribs, Applied Thermal Engineering 58 (2013) 52-60.

[17] Y.L. Zhai, G.D. Xia, X.F. Liu, Heat transfer in the microchannels with fan-shaped reentrant cavities and different ribs based on field synergy principle and entropy generation analysis, International journal of heat and mass transfer 68 (2014) 224-233. 
[18] Y.F. Li, G.D. Xia, D.D. Ma, Characteristics of laminar flow and heat transfer in microchannel heat sink with triangular cavities and rectangular ribs, International Journal of Heat and Mass Transfer 98 (2016) 17-28.

[19] I.A. Ghani, N. Kamaruzaman, N.A.C. Sidik, Heat transfer augmentation in a microchannel heat sink with sinusoidal cavities and rectangular ribs, International Journal of Heat and Mass Transfer 108 (2017) 1969-1981.

[20] I.A. Ghani , N.A.C. Sidik, R. Mamat, Heat transfer enhancement in microchannel heat sink using hybrid technique of ribs and secondary channels, International Journal of Heat and Mass Transfer 114 (2017) $640-655$.

[21] N.A.C. Sidik, M.N.A.W. Muhamad, W.M.A.A, An overview of passive techniques for heat transfer augmentation in microchannel heat sink, International Communications in Heat and Mass Transfer 88 (2017) 74-83.

[22] I.A. Ghani, N.A.C. Sidik, N. Kamaruzaman, Hydrothermal performance of microchannel heat sink: The effect of channel design, International Journal of Heat and Mass Transfer 107 (2017) 21-44.

[23] A. Dewan, P. Srivastava, A review of heat transfer enhancement through flow disruption in a microchannel, Journal of Thermal Science 24 (2015) 203-214.

[24] I.A. Ghani, N.A.C. Sidik, N. Kamaruzaman, The effect of manifold zone parameters on hydrothermal performance of micro-channel HeatSink: A review, International Journal of Heat and Mass Transfer 109 (2017) 1143-1161.

[25] S. Kandlikar, S Garimella, D. Li, S. Colin, M.R. King, Heat transfer and fluid flow in minichannels and microchannels, Elsevier, 2005

[26] T.H. Tsai, R. Chein, Simple model for predicting microchannel heat sink performance and optimization, Heat and Mass Transfer 48 (2012) 789-798. 
[27] D. Liu, S.V. Garimella, Analysis and optimization of the thermal performance of microchannel heat sinks, International Journal of Numerical Methods for Heat \& Fluid Flow 15 (2005) 7-26.

[28] V. Singhal, D. Liu, S.V. Garimella, Analysis of pumping requirements for microchannel cooling systems, ASME 2003 International Electronic Packaging Technical Conference and Exhibition. American Society of Mechanical Engineers, 2003.

[29] S.V. Garimella, V. Singhal, Single-phase flow and heat transport and pumping considerations in microchannel heat sinks, Heat transfer engineering 25 (2004) 15-25.

[30] L. Gosselin, A. Bejan, Tree networks for minimal pumping power, International Journal of Thermal Sciences 44 (2005) 53-63.

[31] P. Canhoto, A.H. Reis, Optimization of forced convection heat sinks with pumping power requirements, International Journal of Heat and Mass Transfer 54 (2011) 1441-1447.

[32] G. Xie, H. Shen, C.C. Wang, Parametric study on thermal performance of microchannel heat sinks with internal vertical Y-shaped bifurcations, International Journal of Heat and Mass Transfer 90 (2015) $948-958$.

[33] W.A. Khan, M.M. Yovanovich, J.R. Culham, Optimization of microchannel heat sinks using entropy generation minimization method. In Semiconductor Thermal Measurement and Management Symposium, 22 ${ }^{\text {nd }}$ IEEE Twenty-Second Annual IEEE, 2006, 78-86.

[34] M. Famouri, K. Hooman, F. Hooman, Effects of thermal boundary condition, fin size, spacing, tip clearance, and material on pressure drop, heat transfer, and entropy generation optimization for forced convection from a variable-height shrouded fin array, Heat Transfer Research 40 (2009) 245-261.

[35] Z. Shi, T. Dong, Entropy generation and optimization of laminar convective heat transfer and fluid flow in a microchannel with staggered arrays of pin fin structure with tip clearance, Energy Conversion and 
Management 94 (2015) 493-504.

[36] Y.L. Zhai, G.D. Xia, X.F. Liu, J. Wang, Characteristics of entropy generation and heat transfer in double-layered micro heat sinks with complex structure, Energy Conversion and Management 103 (2015) 477-486.

[37] L. Chai, G.D. Xia, H.S. Wang, Parametric study on thermal and hydraulic characteristics of laminar flow in microchannel heat sink with fan-shaped ribs on sidewalls-Part 3: Performance evaluation, International Journal of Heat and Mass Transfer 97 (2016) 1091-1101

[38] A. Bejan, Entropy generation through heat and fluid flow, Wiley, 1982.

[39] P. Promvonge, S. Sripattanapipat, S. Kwankaomeng, Laminar periodic flow and heat transfer in square channel with $45^{\circ}$ inline baffles on two opposite walls, International Journal of Thermal Sciences 49 (2010) 963-975.

[40] G.D. Xia, L. Chai, M.Z. Zhou, Effects of structural parameters on fluid flow and heat transfer in a microchannel with aligned fan-shaped reentrant cavities, International Journal of Thermal Sciences 50 (2011) 411-419.

[41] G.D. Xia, L. Chai, H.Y. Wang, Optimum thermal design of microchannel heat sink with triangular reentrant cavities, Applied Thermal Engineering 31 (2011) 1208-1219.

[42] J. Zhang, Y. Zhao, Y. Diao, Y. Zhang, An experimental study on fluid flow and heat transfer in a multiport minichannel flat tube with micro-fin structures, International Journal of Heat and Mass Transfer 84 (2015) 511-520.

[43] F.P. Incropera, Liquid cooling of electronic devices by single-phase convection, Wiley, 1999.

[44] P. Loosen, Cooling and packaging of high-power diode lasers, High-Power Diode Lasers, Springer Berlin Heidelberg 78 (2000) 289-301. 
[45] R.L. Webb, Performance evaluation criteria for use of enhanced heat transfer surfaces in heat exchanger design, International Journal of Heat and Mass Transfer 24 (1981) 715-726. 


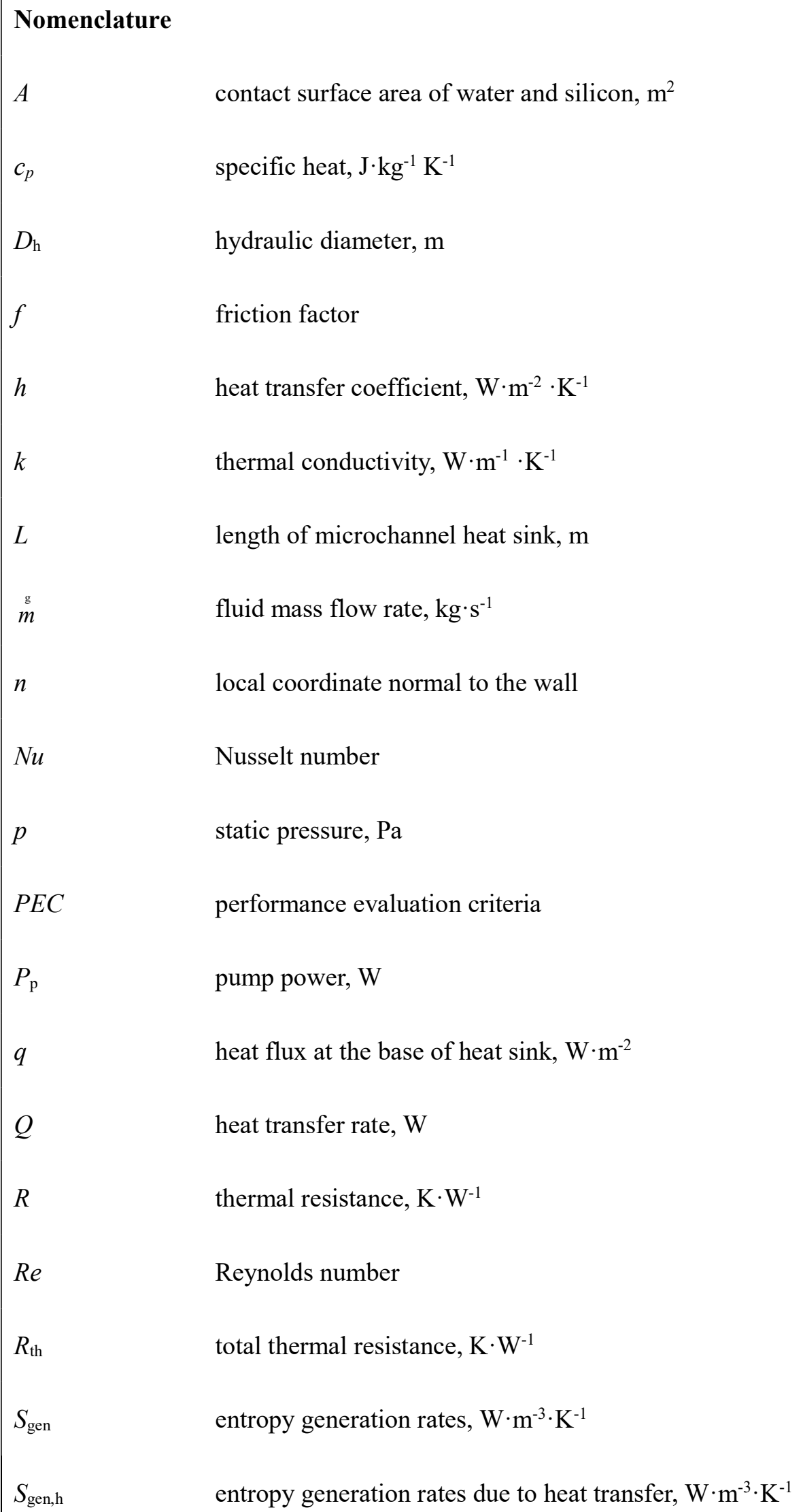




\begin{tabular}{|c|c|}
\hline$S_{\text {gen,f }}$ & entropy generation rates due to fluid friction, $\mathrm{W} \cdot \mathrm{m}^{-3} \cdot \mathrm{K}^{-1}$ \\
\hline$T$ & temperature, $\mathrm{K}$ \\
\hline$T_{\mathrm{a}}$ & ambient temperature, $\mathrm{K}$ \\
\hline$T_{\mathrm{w}}$ & wall temperature at the base, $\mathrm{K}$ \\
\hline$T_{\mathrm{f}}$ & fluid temperature, $\mathrm{K}$ \\
\hline$u, v, w$ & velocity, $\mathrm{m} \cdot \mathrm{s}^{-1}$ \\
\hline$\stackrel{\mathrm{g}}{V}$ & volume flow rate, $\mathrm{m}^{3} \cdot \mathrm{s}^{-1}$ \\
\hline$W$ & width of computational domain, $\mathrm{m}$ \\
\hline$x, y, z$ & three coordinates shown in Fig. 1, m \\
\hline Greek & \\
\hline$\eta$ & ratio \\
\hline$\rho$ & density, $\mathrm{kg} \cdot \mathrm{m}^{-3}$ \\
\hline$\mu$ & dynamic viscosity, $\mathrm{Pa} \cdot \mathrm{s}$ \\
\hline Subscr & \\
\hline 0 & based straight microchannel \\
\hline $\mathrm{a}$ & ambient \\
\hline ave & average \\
\hline cap & capacitive \\
\hline cond & conductive \\
\hline cont & contact surface \\
\hline conv & convective \\
\hline $\mathrm{f}$ & friction factor \\
\hline
\end{tabular}




$\begin{array}{ll}\text { h } & \text { heat transfer } \\ \text { in } & \text { inlet } \\ \text { IM } & \text { interrupted microchannel without ribs } \\ \text { m } & \text { mean } \\ \text { out } & \text { outlet } \\ \text { pp } & \text { pumping power } \\ \text { s } & \text { silicon, entropy generation rate } \\ \text { w } & \text { heat sink base }\end{array}$




\section{Figure captions}

Table. 1 Parameters of the proposed correlations for $\eta_{\mathrm{f}}$ and $\eta_{\mathrm{h}}$.

Fig. 1 Structure of interrupted microchannel heat sinks. (a) interrupted microchannel heat sink, (b) computational domain and (c) rib geometry.

Fig. 2 Two groups of rib geometry. (a) Group 1 with different expansion-constriction profiles (horizontal line, inclined line and ellipsoidal curve) but same ratio and (b) Group 2 with same expansion-constriction profile (inclined line) but different ratios $(0,1$ and $\infty)$.

Fig. $3 \eta_{\mathrm{f}}$ versus $R e$. (a) for IMCHS with $l=0.5 \mathrm{~mm}$, (b) for Group 1 and (c) for Group 2.

Fig. $4 \eta_{\mathrm{h}}$ versus $R e$. (a) for IMCHS with $l=0.5 \mathrm{~mm}$, (b) for Group 1 and (c) for Group 2.

Fig. 5 CFD plots of velocity, pressure and temperature distributions in interrupted microchannel heat sinks $(\operatorname{Re}=441, z=0.25 \mathrm{~mm})$.

Fig. 6 Comparisons of numerical result and prediction of correlations. (a) $\eta_{\mathrm{f}}$ and (b) $\eta_{\mathrm{h}}$.

Fig. 7 Comparison of total thermal resistance. (a) $R_{\mathrm{th}}$ versus $R e$ and (b) $R_{\mathrm{th}} / R_{\mathrm{th}, 0}$ versus $R e$.

Fig. 8 Comparison of term thermal resistance. (a) $R_{\text {cond, }}, R_{\text {conv }}$ and $R_{\text {cap }}$ versus $R e$ and (b) $R_{\text {cond }} / R_{\text {th }}, R_{\text {conv }} / R_{\text {th }}$ and $R_{\text {cap }} / R_{\text {th }}$ versus $R e$.

Fig. 9 Comparison of total thermal resistance. (a) $R_{\text {th }}$ versus $P_{\mathrm{p}}$ and (b) $P_{\mathrm{p}}$ versus $R e$.

Fig. $10 R_{\text {th }}$ versus $P_{\text {p. }}$ (a) for Group 1 and (b) for Group 2.

Fig. 11 Comparison of entropy generation rate. (a) $S_{\text {gen }}$ versus $R e$ and (b) $\eta_{\mathrm{s}}$ versus $R e$.

Fig. 12 Comparison of term thermal resistance. (a) $S_{\text {gen,h }}$ and $S_{\text {gen,f }}$ versus $R e$ and (b) $S_{\text {gen, }} / S_{\text {gen, }}, S_{\text {gen, }} / S_{\text {gen }}$ versus $R e$.

Fig. $13 S_{\text {gen }}$ versus Re. (a) for Group 1 and (b) for Group 2. 
Fig. $14 P E C$ versus Re. (a) for IMCHS with $l=0.5 \mathrm{~mm}$, (b) for Group 1 and (c) for Group 2.

Fig. $15 P E C_{\mathrm{IM}}$ versus Re. (a) for IMCHS with $l=0.5 \mathrm{~mm}$, (b) for Group 1 and (c) for Group 2. 
Table. 1

\begin{tabular}{ccccccc}
\hline & \multicolumn{5}{c}{$\eta_{\mathrm{f}}$} & \multicolumn{3}{c}{$\eta_{\mathrm{h}}$} \\
\cline { 2 - 7 } & \multicolumn{1}{c}{$a$} & $b$ & $c$ & $d$ & $e$ & $f$ \\
\hline IMCHS-R & 0.1755 & 0.348 & -0.01111 & 0.5661 & 0.1417 & 0.0608 \\
IMCHS-BT & 0.1655 & 0.3593 & -0.02645 & 0.4793 & 0.1674 & 0.04735 \\
& & & & & & \\
IMCHS-D & 0.2712 & 0.2612 & -0.04948 & 0.4807 & 0.1625 & 0.05443 \\
IMCHS-FT & 0.274 & 0.2521 & 0.002889 & 0.4968 & 0.1562 & 0.07225 \\
IMCHS-E & 0.2994 & 0.237 & 0.005144 & 0.532 & 0.1478 & 0.07492 \\
\hline
\end{tabular}


Fig. 1

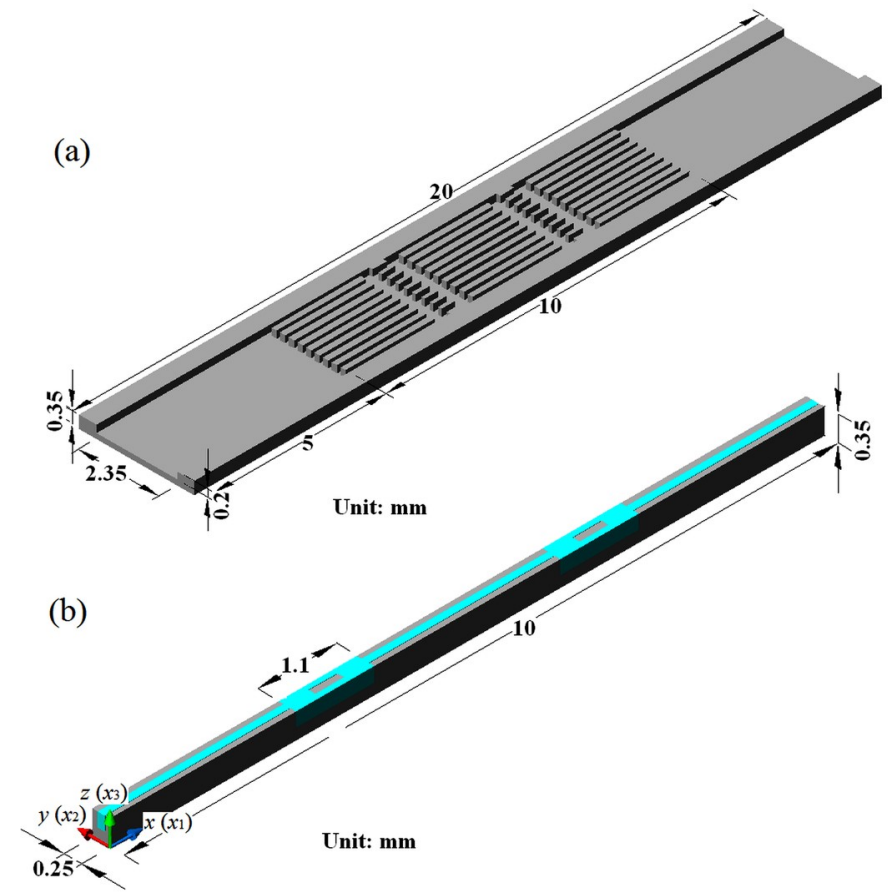

(c)

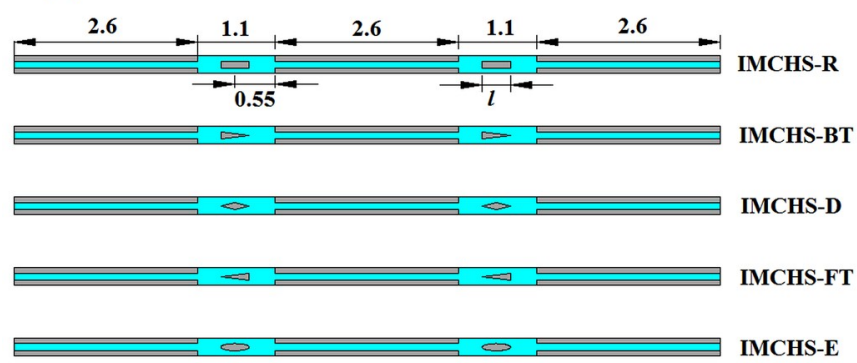

$l=0.2,0.3,0.4$ or 0.5 Unit: $\mathrm{mm}$ 
Fig. 2

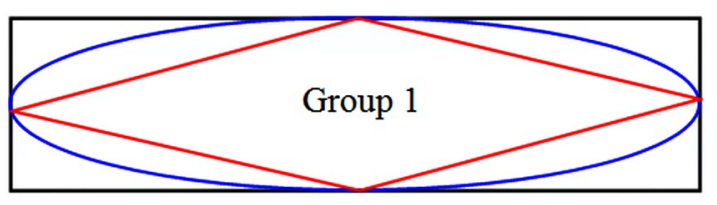

(a)

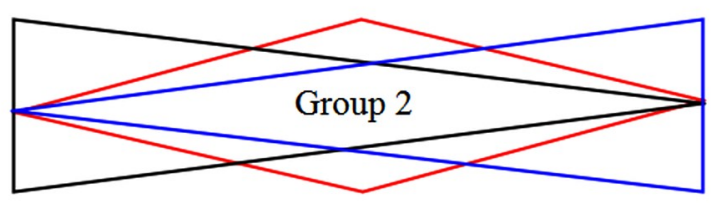

(b) 
Fig. 3

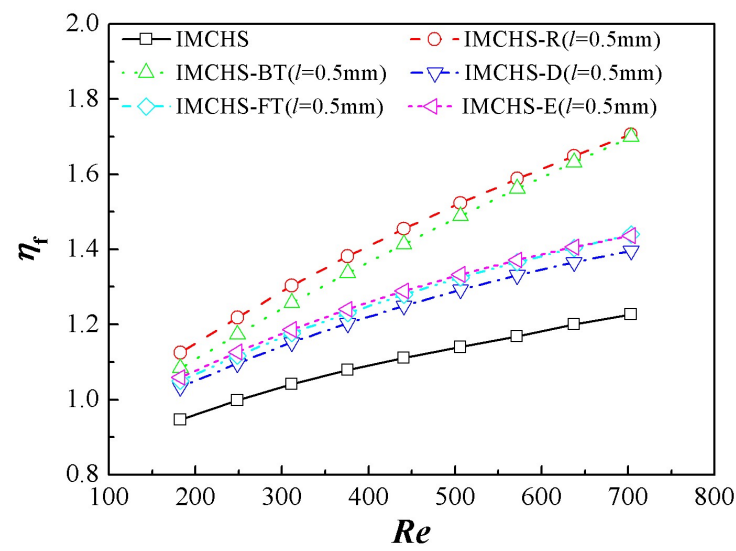

(a)

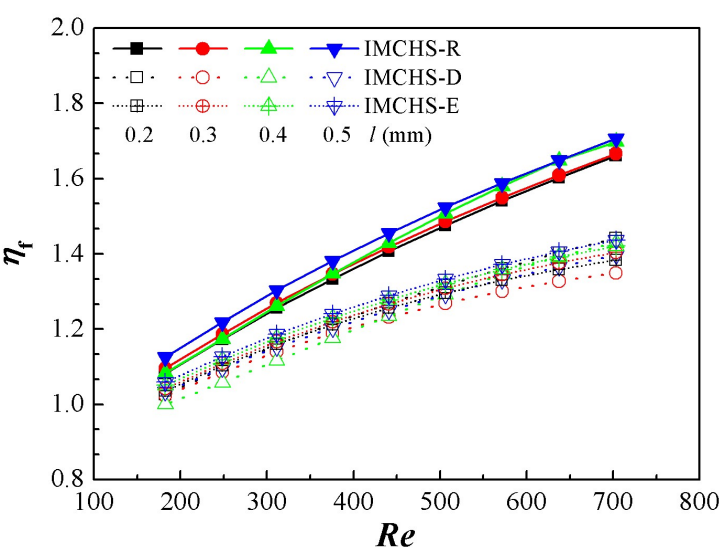

(b)

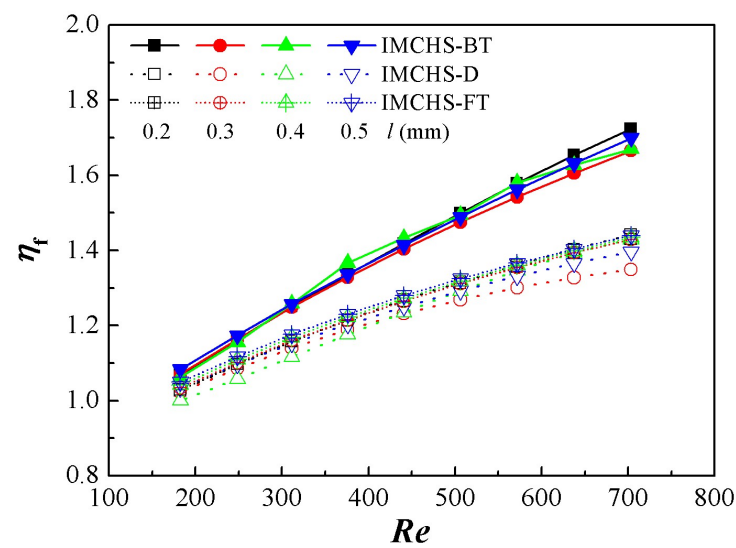

(c) 
Fig. 4

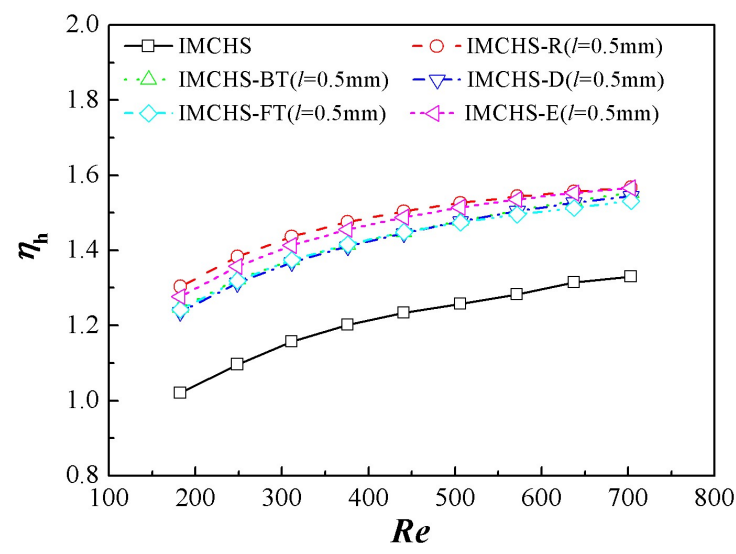

(a)

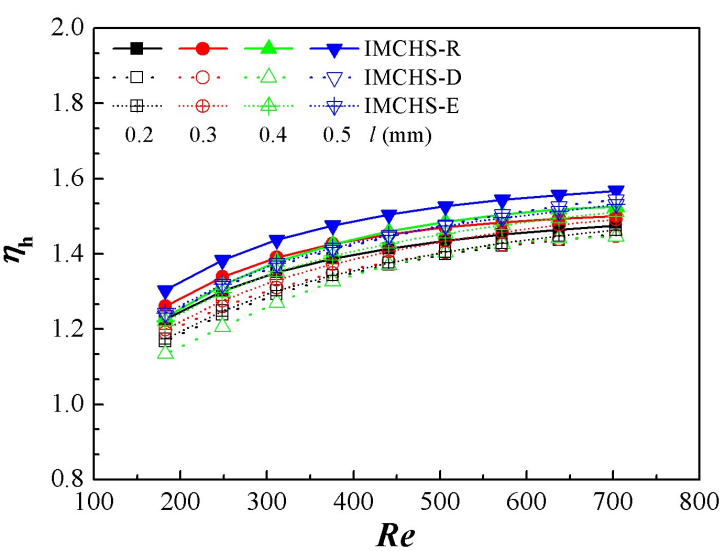

(b)

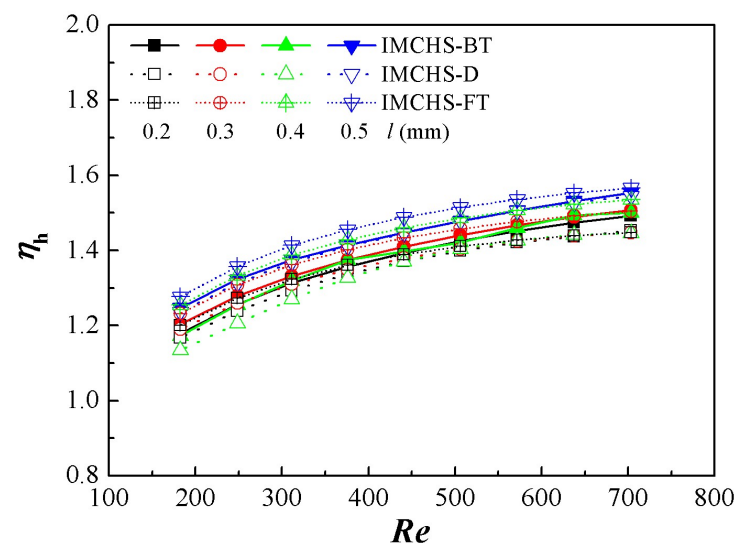

(c) 
Fig. 5
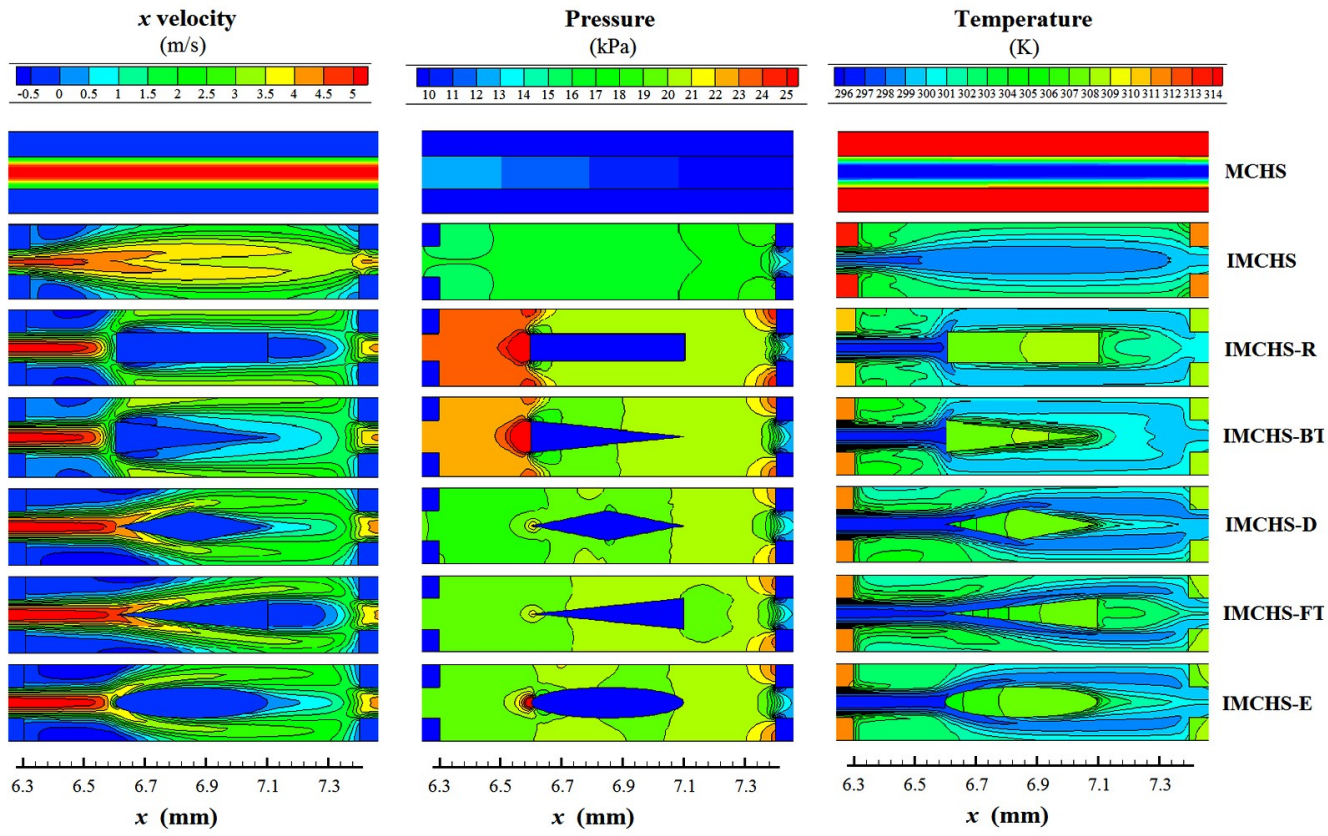
Fig. 6

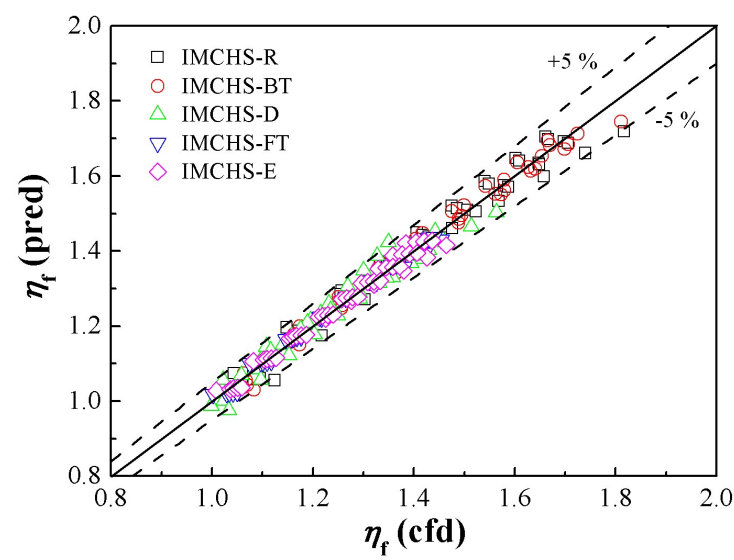

(a)

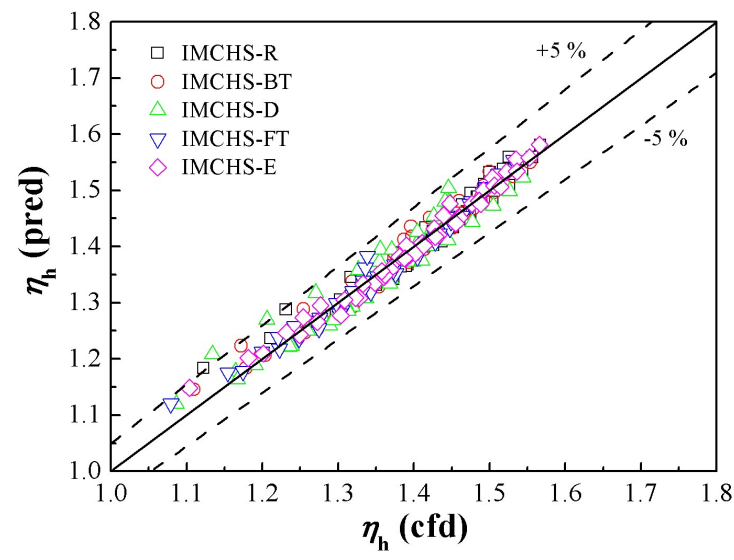

(b) 
Fig. 7

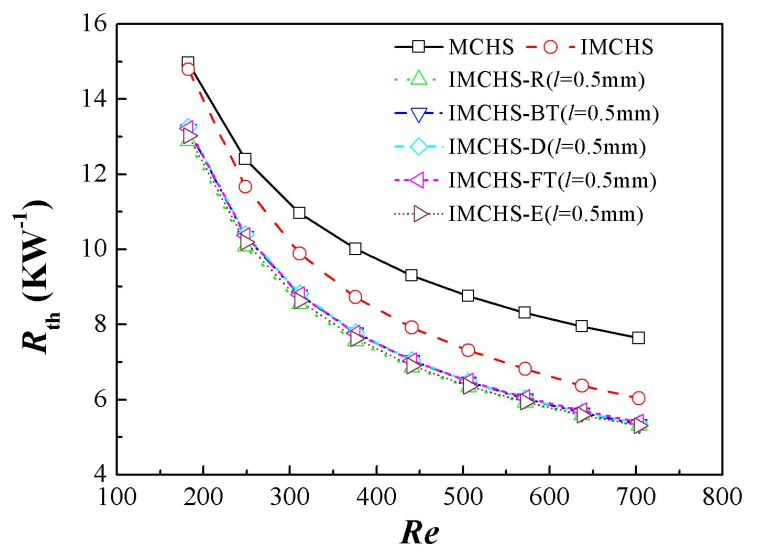

(a)

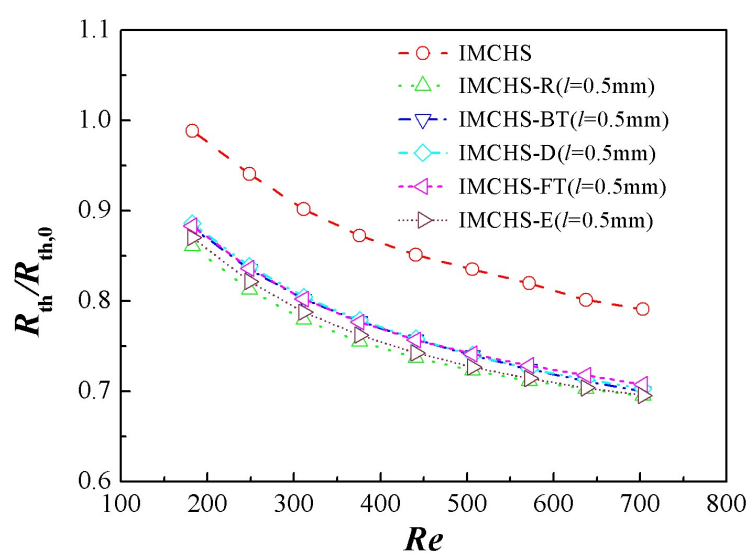

(b) 
Fig. 8

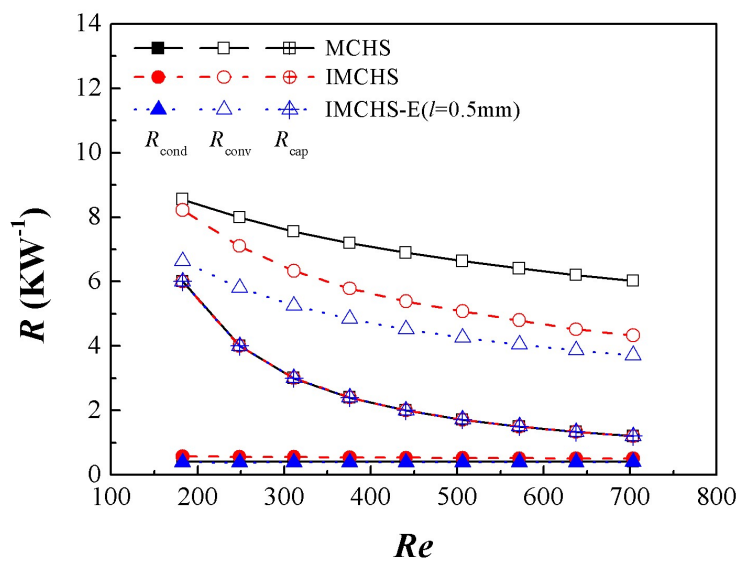

(a)

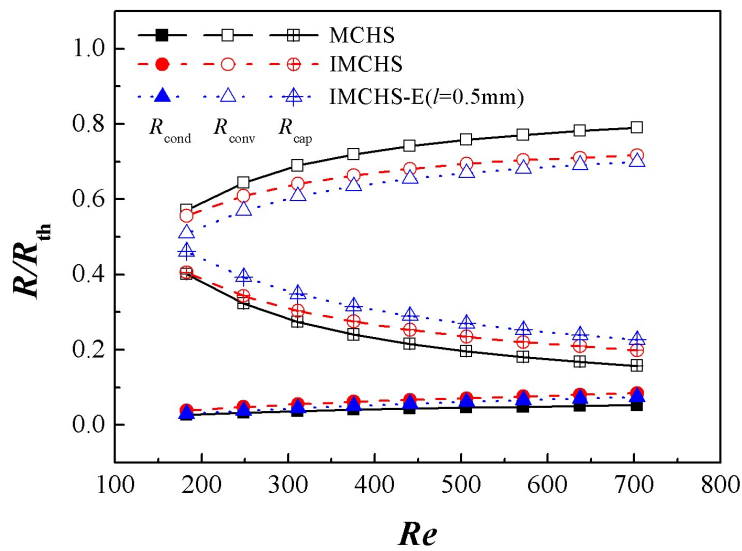

(b) 
Fig. 9

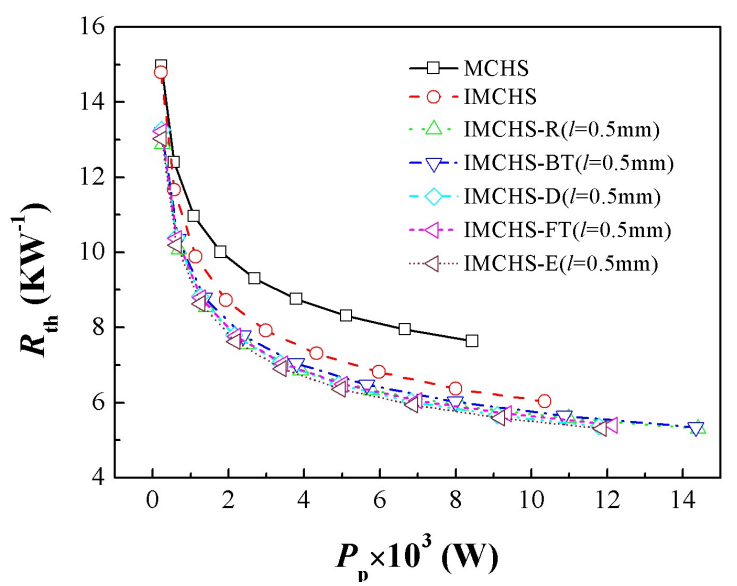

(a)

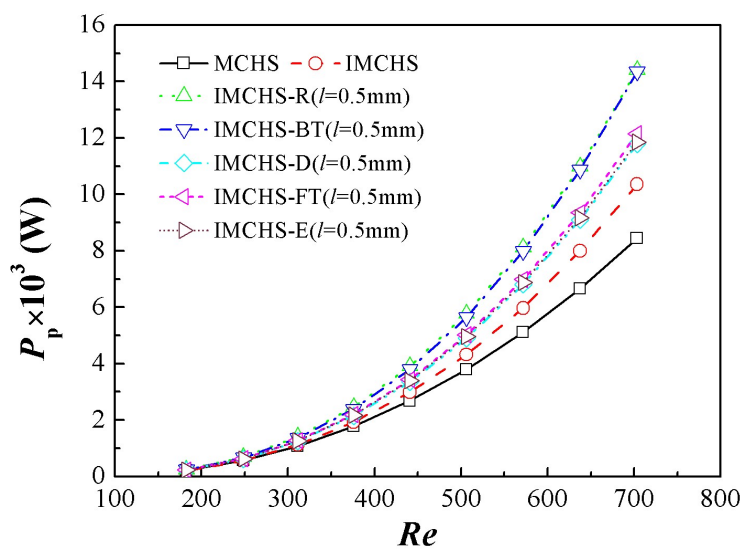

(b) 
Fig. 10

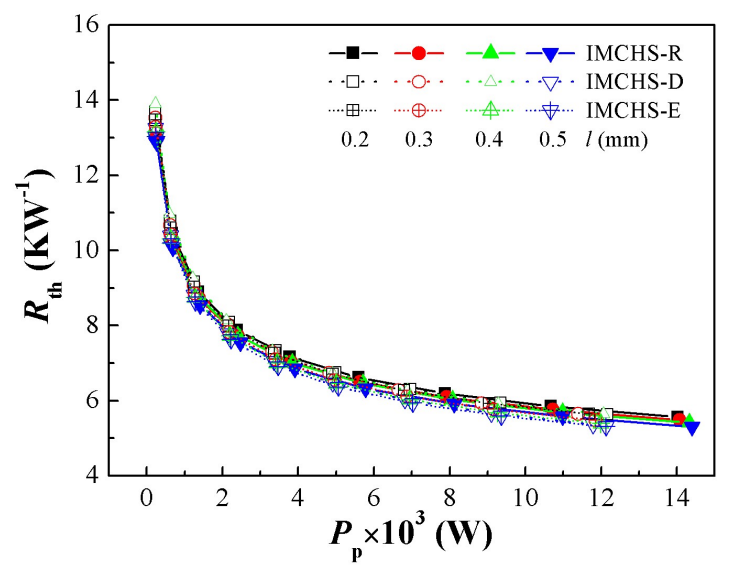

(a)

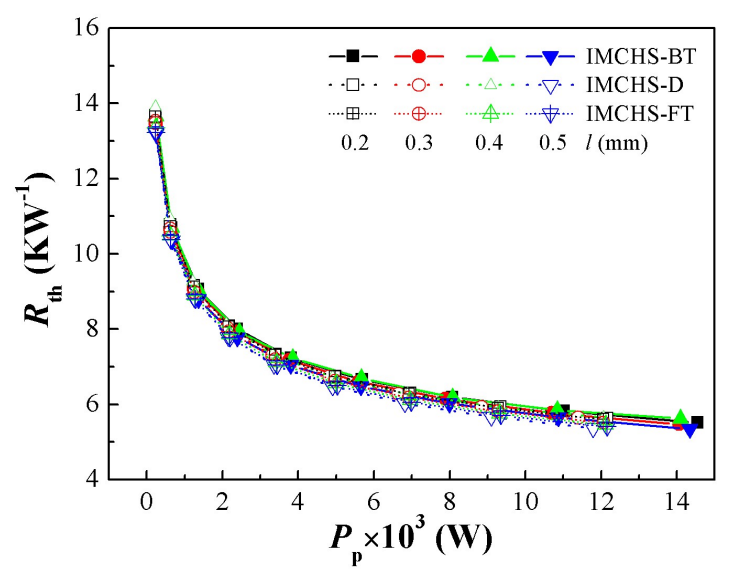

(b) 
Fig. 11

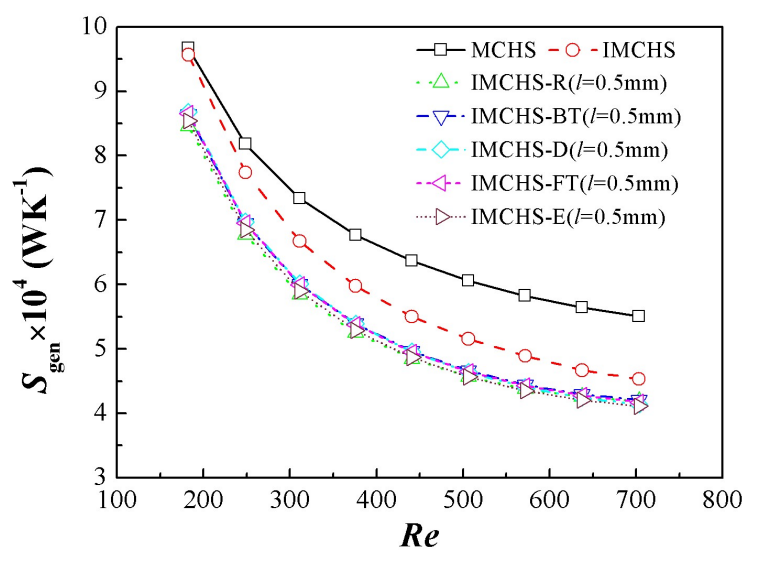

(a)

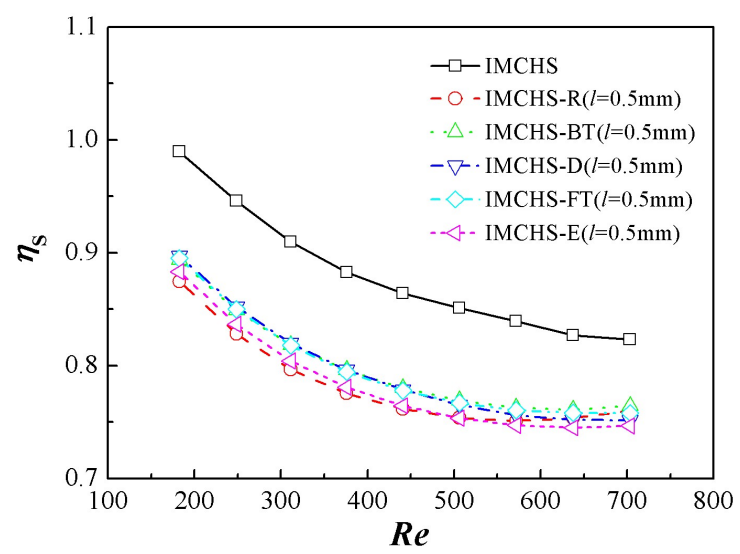

(b) 
Fig. 12

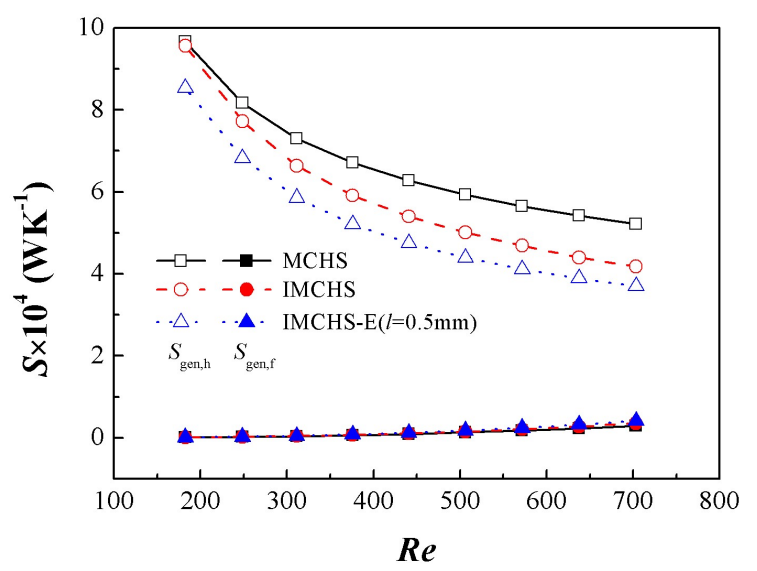

(a)

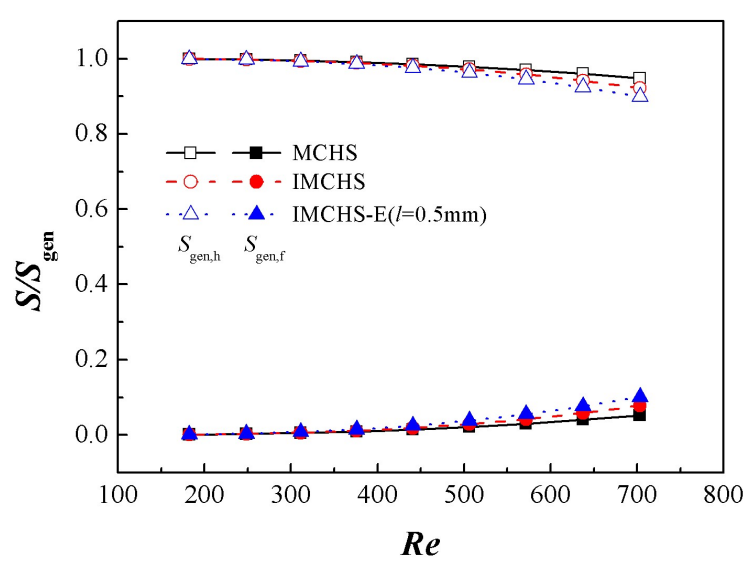

(b) 
Fig. 13

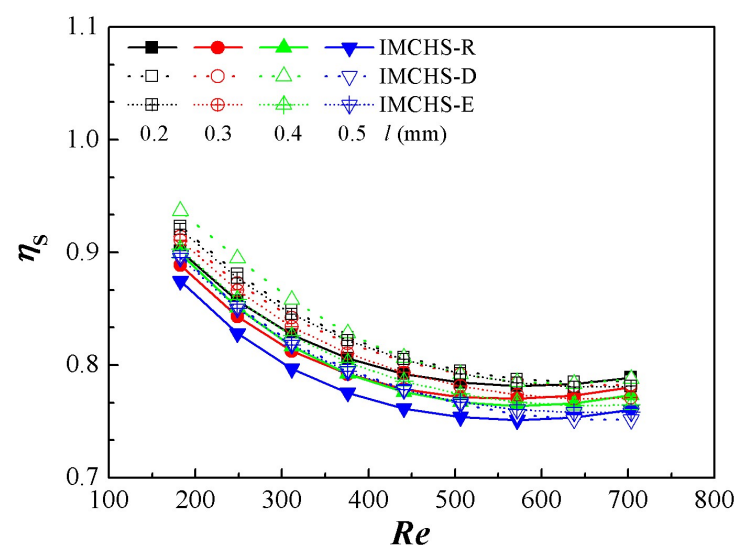

(a)

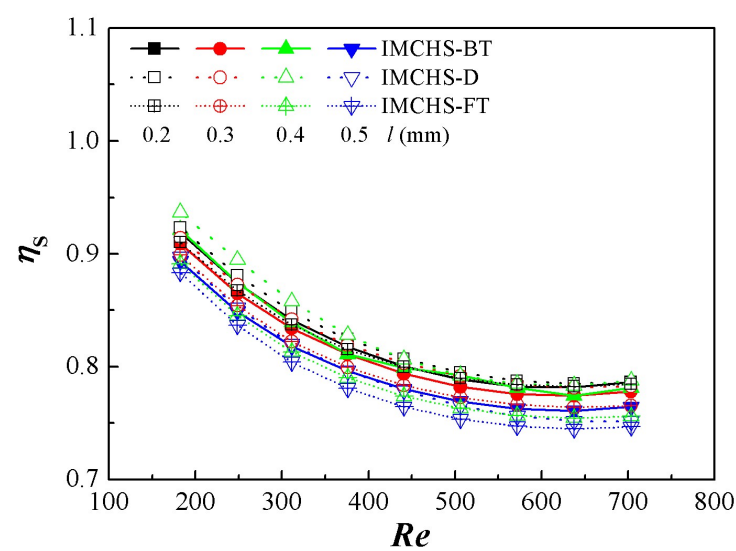

(b) 
Fig. 14

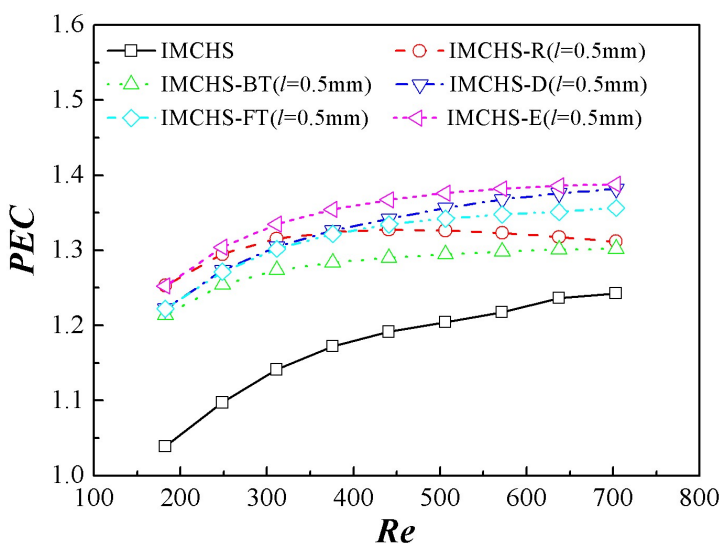

(a)

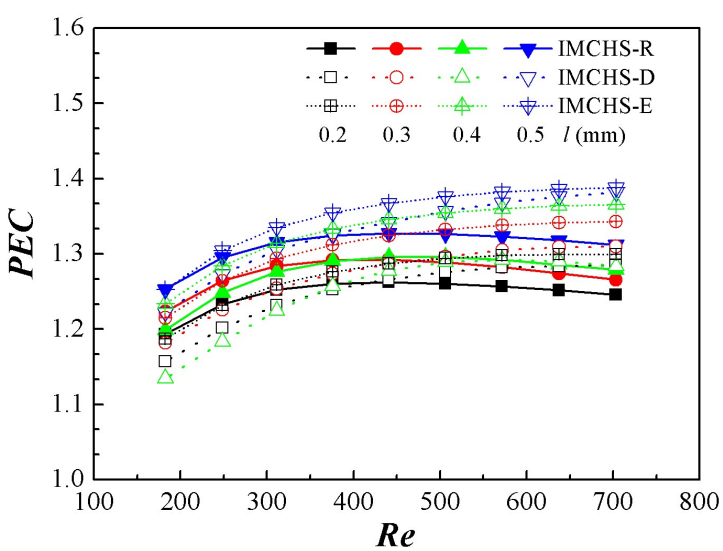

(b)

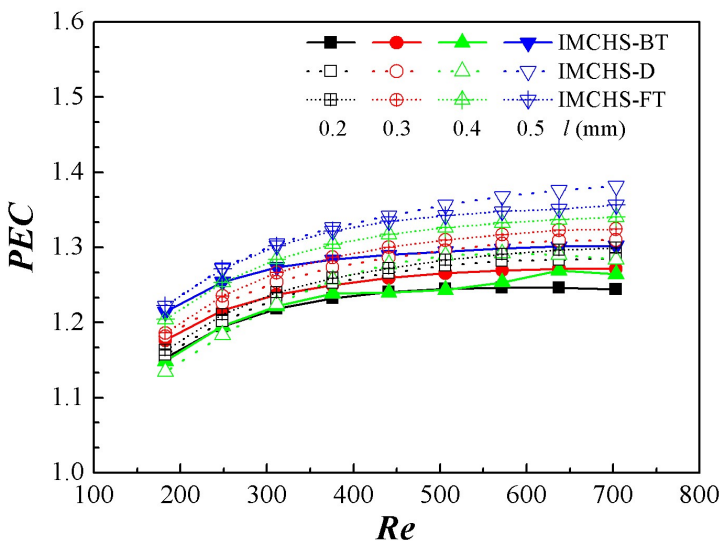

(c) 
Fig. 15

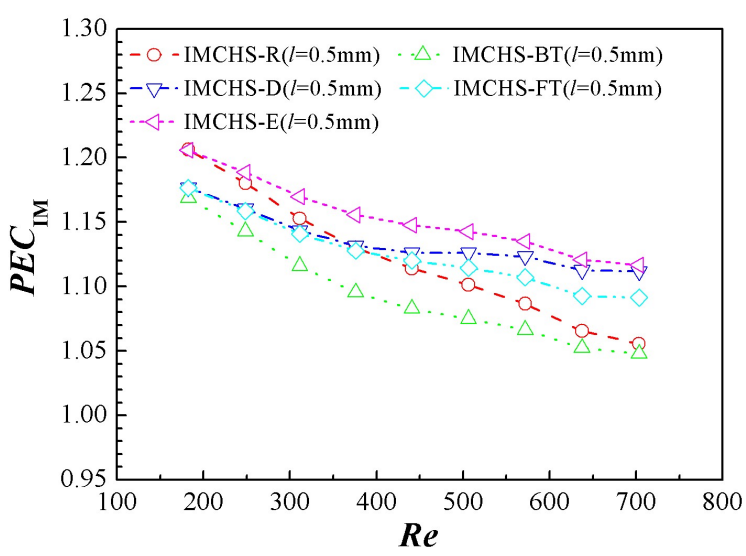

(a)

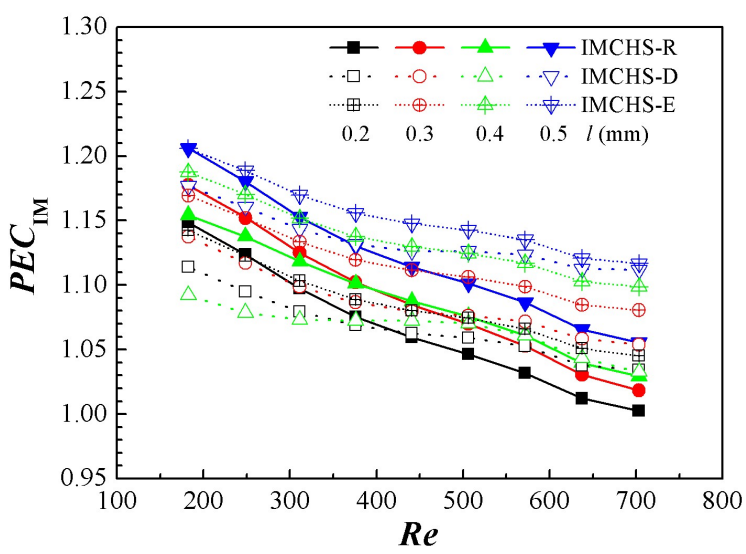

(b)

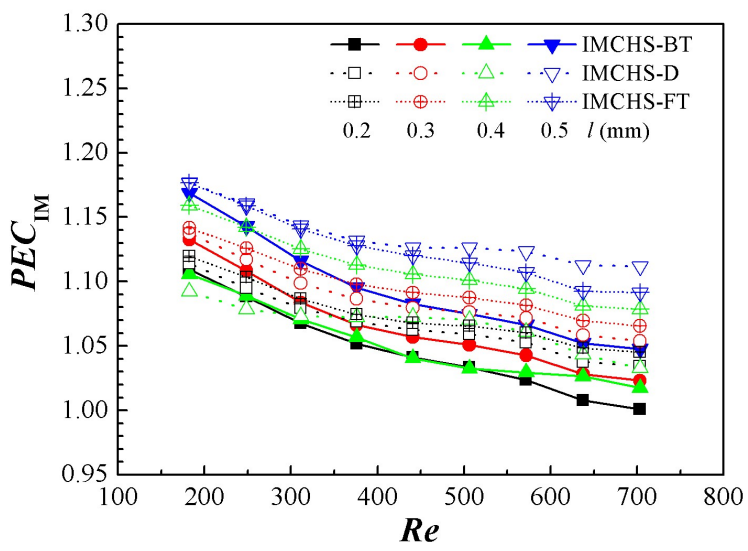

(c) 